\title{
1 Quartz Stressing and Fracturing by Pore Pressure Dropping Down to ${ }_{2}$ Negative Pressure
}

\author{
3 Lionel Mercury,* Emmanuel De Bilbao, Patrick Simon, Hugues Raimbourg, Isabelle Bergonzi, \\ ${ }_{4}$ Claudie Hulin, Aurélien Canizarès, and Kirill I. Shmulovich
}

Cite This: https://dx.doi.org/10.1021/acsearthspacechem.0c00224

Read Online

5 ABSTRACT: In water-bearing porous rocks, pore pressure variations play a 6 major role in deformation, through dissolution-precipitation and fracturing 7 processes. An often-overlooked variation where pressure falls to negative 8 pressure or tension can operate whenever aquifer formations dry out, for 9 instance, in deep storage (nuclear or industrial wastes, long-term $\mathrm{CO}_{2}$ mitigation, 10 short-term energetic resources, etc.). This can generate capillary tension within 11 the aquifers. This study investigates the mechanical effect of such in-pore tension 12 in the surrounding crystal field, through laboratory experiments at the one-pore 13 scale. Microthermometric procedures were carried out on synthetic fluid 14 inclusions to generate large tensile stress and were combined with Raman 15 microspectrometry to visualize the resulting stress fields in the host quartz. For 16 comparison, we numerically modeled the stress field by linear elasticity theory. 17 The experiments demonstrate that significant damage is produced in crystalline

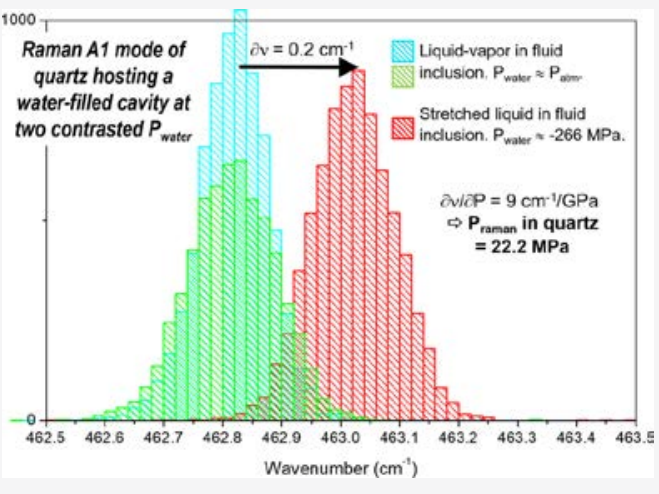
18 materials by the pore tension. Despite the induced stress measured by micro-

19 Raman spectrometry to remain moderate, it is able to fracture the quartz. The volume of the cavity is a prominent controlling 20 parameter for the stress amplitude. The crystalline heterogeneities of the solid are another major parameter for localizing the mean 21 weak stress and accumulating overstress. Our results call for bringing pore-scale micromechanics into the safety assessment of the 22 geological storage of various wastes inside depleted aquifers. They also show the magnifying effect of heterogeneities on propagating 23 stress and localizing it along certain directions, promoting the final failure of water-bearing minerals, rocks, or pore networks.

24 KEYWORDS: tensile strength, pore rock damage, storage safety, Raman scattering, quartz weakening, fluid inclusions

\section{INTRODUCTION}

25 Modern societies have growing interest in water-depleted 26 aquifers for various storage operations, which are often 27 accompanied by enhanced drying and increasing water tension 28 (liquid negative pressure) in the liquid infilling the pores. 29 Water tension in pores does induce a stress in the solid lattice 30 around the fluid-bearing cavity, which is largely overlooked 31 while possibly conducive to crystal failure. Even in the 32 subcritical cracking regime, low stresses, possibly amplified at 33 the tip of microcracks because of pre-existing flaws in the rock, 34 and slow processes, persisting in the long term, can result in 35 rock failure (e.g., refs. ${ }^{1,2}$ ).

36 The micromechanics of such situations can be treated 37 similarly to the drying-driven damage occurring in rocks at 38 variable humidities (e.g., refs. ${ }^{3,4}$ ). The theory involves the role 39 of variable water saturation, of capillary bridging forces 40 crossing the micro/nanopores, and of disjoining forces that 41 hinder adsorption of water in nanopores, all processes that 42 cause strain softening and microcracking. In all these studies, it 43 is difficult to distinguish at the relevant scale the mechanical 44 role of field stress created by pore tension from stress corrosion of chemical origin, which contributes to water weakening. ${ }^{5,6}$ In 45 particular, imaging and quantification of the microstress in the 46 solid network, before and after fluid tension sets up in the 47 pores, have been missing until now.

The challenges associated with this area of research are first 49 in materials science in which several examples of tension- 50 driven fracture processes still require mechanistic explanations 51 or quantification. While sol-gel processing explains how 52 drying-driven stress causes bodies to crack, how nanoparticle 53 suspensions dry is much less understood, depending 54 appreciably on molecular-scale physics combining capillary 55 and viscous forces (e.g., refs. ${ }^{7,8}$ ). How cementitious materials 56 dry is also of interest. There is little doubt there, ever since the 57 pioneering work ${ }^{9,10}$ showing that the main driving force is 58

Received: August 19, 2020

Revised: January 21, 2021

Accepted: January 21, 2021 

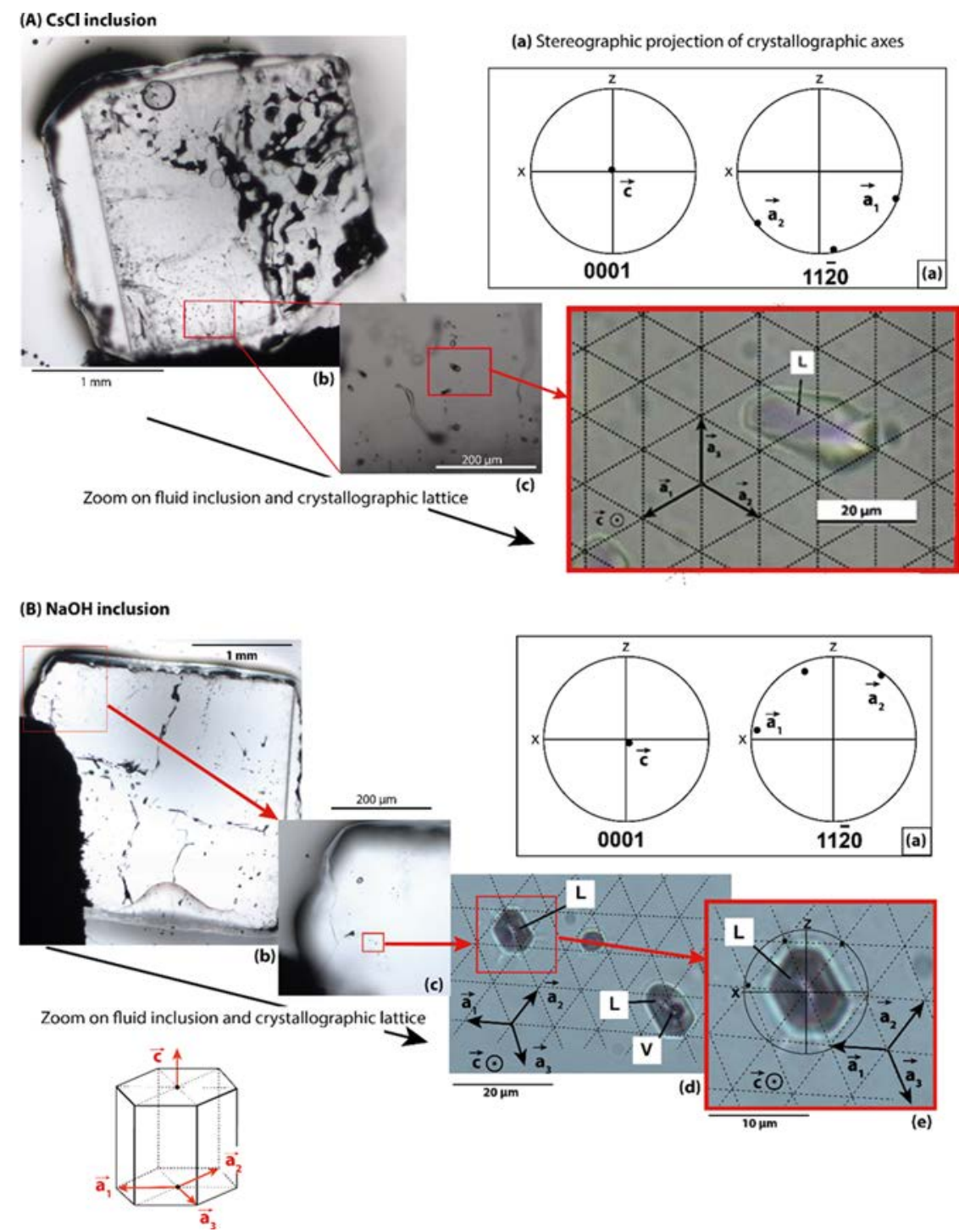

Figure 1. Photomicrographs and EBSD measurements of the two inclusions of interest ( $\mathrm{L}=$ liquid aqueous solution; $\mathrm{V}=\mathrm{vapor})$. A. CsCl inclusion entirely filled by aqueous solution. B. $\mathrm{NaOH}$ inclusion. For each inclusion, two stereoplots show the orientation of the [0001] and [11 $\overline{2} 0]$ axes within the host quartz, located perpendicular and parallel to the polishing plane, respectively. The redundant coordinate system $\left(a_{1}, a_{2}, a_{3}, c\right)$ is used (hexagonal lattice).

59 capillary tension, possibly relayed in the smallest spaces by 60 disjoining pressure effects (e.g., refs ${ }^{11-14}$ ). However, the main 61 challenges are the role these processes may play in crystalline 62 natural rocks, as for hydrosystems subjected to drying 63 operations. The issue is understanding if and how these 64 processes are able to generate new pore-scale stress fields and 65 modify the cracking network of a rock as well as the air/water 66 permeability throughout the aquifer. For illustration, nuclear 67 waste storage in low-permeability rocks requires shaft and drift 68 mining that dries out the rocks, expected over a few meters 69 around galleries (e.g., refs ${ }^{15-19}$ ). On the one hand, ventilation 70 of the tunnels promotes high tensions that can reach -100 $71 \mathrm{MPa}$ or more. ${ }^{19}$ On the other hand, geochemical traces of air 72 introduction are recorded up to 21 meters from the ventilated 73 tunnel, whereas the formation is assumed to be water-saturated 74 at such a distance (e.g., refs. ${ }^{18,20}$ ). The second illustration is the 75 injection of (supercritical) $\mathrm{CO}_{2}$ into deep aquifers. This 76 provokes intense drying in the near field of the wellbore with 77 strong and counterintuitive capillary effects. ${ }^{21-23}$ Third, 78 enhanced-oil recovery operations play with successive sequences of various fluid injections (air, liquid, and oil). 79 The water invasion in dried rocks is known to induce 80 weakening effects without a clear viewpoint on the active 81 mechanisms (e.g., refs. ${ }^{24,25}$ ). Fourth, salt damage to cultural 82 heritage stones is mostly interpreted as the role of 83 crystallization pressure but is accompanied by significant 84 desaturation and capillary effects (e.g., refs. ${ }^{14,26}$ ).

The key objective of this contribution is therefore to address 86 drying-driven microcracking mechanisms, which may down- 87 grade the material's quality and impact the physical properties 88 (transmissivity and safety storage) of the damaged rock. Two 89 experiments were designed with fluid inclusions synthesized in 90 monocrystalline quartz and filled with aqueous solutions. As 91 such, they stand for pores in crystalline and cemented materials 92 but cannot be directly used to draw conclusions on natural 93 fluid inclusions that contain less structural water and lower 94 dislocation densities than synthetic fluid inclusions (SFIs). The 95 occluded liquid was put under variable high tensions with 96 various time frames, according to a microthermometric 97 procedure (closed univariant system) (e.g., $\operatorname{refs}^{27-31}$ ). The 98 
99 Raman shift of the quartz was mapped and shown to vary as a 100 function of the in-pore tension, therefore visualizing the 101 internal stress fields in the host crystal.

102 Two levels of damage occurred during the course of these 103 experiments: optically invisible damage at the microscale and 104 visible fracturing of the host quartz. The experimental 105 investigations were compared to a numerical simulation 106 based on isotropic linear elasticity. The distance of influence 107 of the in-pore tension inside the host quartz appears strikingly 108 larger than expectable, while the simulated and measured 109 distributions of stress in the crystal match.

\section{MATERIALS AND METHODS}

110 2.1. Samples. SFIs have been synthetized in two 111 monocrystalline pieces of hydrothermal quartz. After thermal 112 fracturing, the quartz pieces were healed at high pressure and 113 temperature $(P, T)$ by $\mathrm{SiO}_{2}$ overgrowth, in the presence of an 114 aqueous solution of known composition. ${ }^{30}$ One quartz piece 115 was healed in the presence of a $\mathrm{CsCl} 13.6 \mathrm{M}$ (69.6 wt \%) brine, 116 at $630 \mathrm{MPa}$ and $480{ }^{\circ} \mathrm{C}$ for 20 days. Under ambient 117 conditions, $\mathrm{CsCl}$ inclusions contain either two phases (a 118 bubble of gas and a liquid phase) or a monophasic liquid-only 119 phase (Figure 1). This trapped solution is known to sustain the 120 most extreme tensile strength ever recorded in aqueous fluids ${ }^{30}$ 121 and therefore will serve to install super-high tensile stress. In 122 addition, the decreasing water activity associated with the $\mathrm{CsCl}$ 123 electrolyte ( 0.57 from Pitzer calculations at $25^{\circ} \mathrm{C}^{32}$ ) may 124 contribute to water weakening by enhancing solubility, 125 especially at the stress concentration zones.

126 The other quartz piece was hydrothermally treated at 500 $127{ }^{\circ} \mathrm{C}, 600 \mathrm{MPa}$ for 45 days, in the presence of a $0.2 \mathrm{M} \mathrm{NaOH}$ 128 dilute solution. Under ambient conditions, these $\mathrm{NaOH}$ 129 inclusions also contain either two phases-a bubble of gas 130 and a liquid phase- or a monophasic liquid-only phase (Figure 131 1). The dilute $\mathrm{NaOH}$ solution trapped under high-density 132 conditions is prone to install liquid tension at room 133 temperature $(\mathrm{RT})^{30}$ and so serves to exhibit long-term tensile 134 stress.

135 These two electrolytes make the quartz more soluble, 136 especially under the synthesis conditions $\left(0.63 \mathrm{GPa}, 480{ }^{\circ} \mathrm{C}\right.$, 137 and 20 days for the first; $0.6 \mathrm{GPa}, 500{ }^{\circ} \mathrm{C}$, and 45 days, for the 138 second), so they may produce inclusions with very good inner 139 surfaces well prone to hosting superheating processes. 140 According to previous datasets, ${ }^{30}$ and as mentioned above, ${ }_{141} \mathrm{CsCl}$ solutions can sustain the most extreme tensile strength 142 ever recorded in aqueous fluids, while dilute $\mathrm{NaOH}$ solutions 143 are efficiently superheated at RT or below (high-density 144 samples). Additionally, the role of both electrolytes during 145 these experiments should have enforced the tensile stress by a 146 chemical "weakening" effect. However, considering the slow 147 kinetics of the dissolution-precipitation process under the 148 thermometric cycle conditions, this effect is certainly of 149 secondary importance.

150 Electron back-scattered diffraction (EBSD) was used to 151 determine the crystallographic orientation of the quartz 152 samples around the fluid inclusions, after the microthermo153 metric studies, to prevent any electron-driven defects. To do 154 so, thin sections were chemically polished with a colloidal silica 155 suspension $(0.04 \mu \mathrm{m}$ colloidal silica suspension, Struers $)$ and 156 then carbon-coated to prevent charging effects. All sections 157 were tilted by $70^{\circ}$ to the electron beam to produce clear 158 diffraction patterns. Data were collected using an EDAX 159 PEGASUS EDS/EBSD system and processed with OIM DC
6.4 software (manufacturer EDAX, Mahwah, USA), available at 160 BRGM (Orléans, France). The working distance was of about 161 $18 \mathrm{~mm}$, at an accelerating voltage of $25 \mathrm{kV}$.

The samples are platelets containing the $a$ - and $b$-axes and 163 thus perpendicular to the crystallographic c-axis (Figure 1). 164

2.2. Method 1: Establishing Tensile Conditions in the 165 Pore Fluid. High tension can be produced in a liquid 166 occluded inside a closed cavity, by making it monophasic 167 through increasing temperature and then cooling down this 168 monophasic liquid below the saturation curve along a constant 169 volume trajectory. This procedure was largely used in the past 170 to study the phase diagram of tensile water (e.g., refs. ${ }^{27-31}$ ) 171 and the corresponding changes of phase equilibria (e.g., 172 refs. $^{33,34}$ using fluid inclusions; refs. ${ }^{35,36}$ using Berthelot tubes). 173

The starting pore material generally contains a biphasic 174 liquid + vapor assemblage $(\mathrm{L}+\mathrm{V})$. With progressive heating, 175 the liquid density and bubble pressure change, and the trapped 176 liquid progressively invades the whole inclusion space (A to B 177 path, Figure 2) up to a particular density where there is no $178 \mathrm{f} 2$

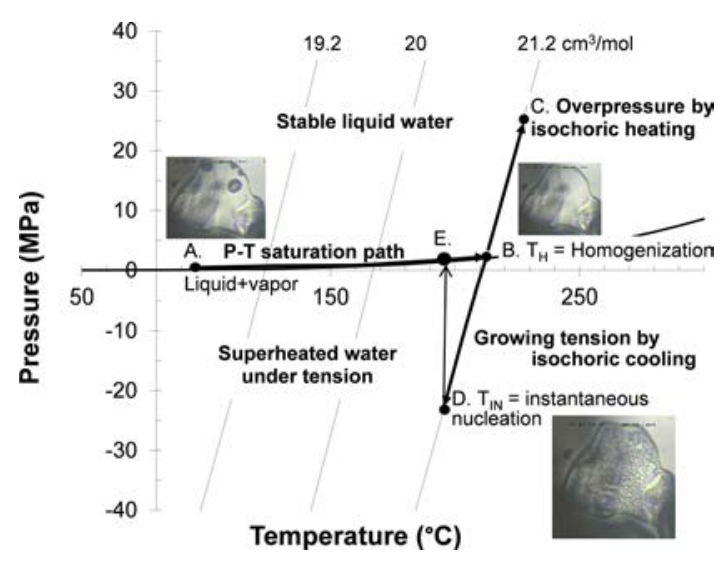

Figure 2. Phase diagram of pure water in the $\mathrm{P}-\mathrm{T}$ space, calculated with the IAPWS-95 equation of state. ${ }^{37}$ Each isochore is labeled with the molar volume in $\mathrm{cm}^{3} \cdot \mathrm{mol}^{-1}$. The $\mathrm{CsCl}$ inclusion micrographs illustrate the fluid content present in the cavity at each characteristic step.

more vapor (point B, Figure 2). The inclusion is then 179 recognized to be homogenized at the corresponding 180 "homogenization temperature" $\left(T_{\mathrm{H}}\right)$. Further heating drives 181 the $P-T$ conditions in the inclusion along the isochore curve 182 inside the stable domain of liquid ( $B$ to $C$ path, Figure 2). The 183 second step is the progressive cooling of the sample, which 184 follows the isochoric path as long as the inclusion remains 185 homogeneously filled with liquid ( $\mathrm{C}$ to $\mathrm{D}$ path without 186 nucleation at $\mathrm{B}$, Figure 2). Once $T_{\mathrm{H}}$ is crossed without bubble 187 nucleation, the monophasic liquid becomes metastable; that is, 188 it is less stable than the liquid-vapor assemblage. The 189 nucleation does not occur as long as the energy cost of the 190 vapor-liquid interface fabrication is higher than the gain 191 afforded by the bulk energy of the most stable phase. ${ }^{31,38}$ Such 192 a monophasic liquid is superheated (located to the right of the 193 saturation curve) and follows an isochoric cooling down to a 194 certain temperature at which a bubble appears suddenly. This 195 is the instantaneous nucleation temperature $\left(T_{\mathrm{IN}}\right)$, which is 196 always located within the tensile domain: nucleation in fluid 197 inclusions disobeys the saturation conditions. After nucleation, 198 the newly formed LV assemblage moves instantaneously back 199 to the saturation curve conditions ( $\mathrm{D}$ to E path, Figure 2). This 200 
201 procedure fabricates tensile water similar to that retrieved at 202 the high capillary degree that forms under drying conditions. 203 All thermal sequences were carried out on a Linkam 204 heating-cooling stage THMS600, at a slow rate $\left(2{ }^{\circ} \mathrm{C} / \mathrm{min}\right)$ to 205 avoid any temperature overshoot and guarantee a thermal 206 equilibrium at each set point.

207 2.3. Method 2: Measuring the Stress in the Container. 208 In situ Raman spectrometry can be used to record the 209 temperature/pressure shift of a solid material because of the 210 anharmonicity of a Raman-active vibration mode. ${ }^{39}$ Anharmo211 nicity is generally considered to have two contributions: 212 explicit ones (as phonon-phonon interactions) and implicit 213 ones coming from changes in bond lengths (under $P$ or $T$ 214 variations) (e.g., refs. ${ }^{40,41}$ ). Both will lead to the wavenumber 215 shift of vibration modes upon external solicitations such as 216 temperature or hydrostatic pressure. A previous study on 217 quartz $^{42}$ investigated the changes in wavenumber and line218 width of the 206 and $464 \mathrm{~cm}^{-1} \mathrm{~A}_{1}$ Raman modes of $\mathrm{SiO}_{2}$ from 21923 to $800{ }^{\circ} \mathrm{C}$ and from $0.1 \mathrm{MPa}$ to $2.1 \mathrm{GPa}$. It was observed 220 that, under hydrostatic stress, the wavenumber shift of the 464 $221 \mathrm{~cm}^{-1}$ peak at RT $\left(23{ }^{\circ} \mathrm{C}\right)$ depends linearly on pressure up to $2220.5 \mathrm{GPa}: d / d P=8.7 \mathrm{~cm}^{-1} / \mathrm{GPa}$. The wavenumber shift for the $223206 \mathrm{~cm}^{-1}$ mode also has linear pressure dependency, twice as 224 much at $\mathrm{d} / \mathrm{d} P=20 \mathrm{~cm}^{-1} / \mathrm{GPa}$. Schmidt and Ziemann ${ }^{42}$ 225 considered an isotropic stress according to the Grüneisen 226 formalism, with a linear dependence between stress and Raman 227 wavenumber. This linear approach is certainly the most reliable 228 to treat the complex case of a noncubic crystalline symmetry, 229 noninfinite crystal because of the inclusion vicinity, and 230 nonuniform force field and is the method used here, assuming 231 that the stress field induced by pressure change in the fluid 232 inclusion is similar to hydrostatic stress and considering the 233 isotropy in $(\mathrm{a}, \mathrm{b})$-plane. As no resonant Raman scattering effect 234 occurs here, the stress/Raman shift relation obtained by 235 Schmidt and Ziemann ${ }^{42}$ with a 514.5 nm laser can be used for 236 any other nonresonant Raman excitation laser line.

237 The measurements were performed on a Renishaw inVia 238 Reflex spectrometer, using the $633 \mathrm{~nm}$ excitation line of a He$239 \mathrm{Ne}$ laser (less than $10 \mathrm{~mW}$ on the sample). The grating was 2401800 grooves $/ \mathrm{mm}$, giving a wavenumber step between two 241 adjacent pixels of the charge-coupled device equal to 0.97 $242 \mathrm{~cm}^{-1}$. Each mapping measurement was performed after a 243 wavenumber calibration procedure of the spectrometer on its 244 internal silicon reference sample $\left(520.5 \mathrm{~cm}^{-1}\right)$, without moving 245 the quartz sample, which ensures the calibration state and 246 promotes the best possible reproducibility. The calibration was 247 systematically checked after map acquisitions and was stable 248 within an accuracy much better than $\pm 0.1 \mathrm{~cm}^{-1}$ over $24 \mathrm{~h}$ (no 249 detectable change of the $520.5 \mathrm{~cm}^{-1}$ position). The micro250 scope (DM2500 Leica) lens compatible with this configuration 251 was a Leica $50 \mathrm{X}$ long front distance $(\mathrm{NA}=0.50)$. Each 252 individual Raman spectrum was obtained with an accumulation 253 time of $10 \mathrm{~s}$. Because of the small diameter of the Raman spot $254(\approx 2 \mu \mathrm{m})$ and the size of the inclusions, maps of around 7600 255 points were acquired, with an acquisition total time reaching $25620 \mathrm{~h}$. The map acquisitions were performed in the Renishaw 257 StreamlineHR mode, optimizing the acquisition time and the 258 vertical resolution (equivalent to a confocal mode), here 259 estimated to be better than $2 \mu \mathrm{m}$.

260 Spectra were treated with Renishaw Wire 3 software. The 261 Raman spectra were not baseline-corrected but directly fitted 262 with a Gauss-Lorentz (G/L hereafter) profile, to involve even 263 the tiniest distortions in the analysis. Very small differences between mono- and biphasic conditions could thus be probed 264 because the spectra were acquired with strictly identical 265 conditions (optical configuration and temperature), apart from 266 the pressure inside the inclusion. No Bose-Einstein thermal 267 correction was performed ${ }^{43}$ because Raman shifts were 268 compared at identical temperatures under two different 269 pressure conditions (monophasic and biphasic regimes). ${ }^{39} 270$

2.4. Method 3: Super-Stressing the Container toward 271 Failure. Two methods were used to establish whether the 272 stress induced in quartz by the in-pore tension was able to 273 provoke the quartz failure. First, the characteristics of the $\mathrm{CsCl} 274$ fluid inclusion allowed us to subject it to high tension 275 cyclically. The procedure was simply to put the inclusion at 276 various temperatures of measurements $\left(T_{\text {MEAS }}\right)$ corresponding 277 to different high tensions and leave the inclusion in this 278 monophasic metastable state until cavitation occurs, bringing 279 back the inclusion to the LV equilibrium state. Then, the 280 inclusion was homogenized and again cooled down to a certain 281 $T_{\text {MEAS }}$ pursuing the cycle. From a mechanical point of view, 282 these repeated stress conditions can damage the solid 283 depending on the lattice's defaults, the intensity of the stress, 284 and the number of cycles.

285

Second, the $\mathrm{NaOH}$ fluid inclusions allowed us to install 286 high-tension conditions at RT, so the liquid tension could be 287 readily maintained over a long time. Therefore, stress is 288 accumulated within the sample over time, as long as bubbles 289 are absent (easily verified by optical observations) in the 290 superheated inclusions: this was a permanent or "enduring" 291 tension experiment, corresponding to purely static stress 292 conditions.

2.5. Method 4: Simulating the Stress in the Host 294 Crystal as a Function of in-Pore Fluid Tension. Numerical 295 simulations of the experiments were performed by finite 296 element analysis (FEA hereafter) using Comsol Multiphysics 297 software for a deeper understanding of the stress change 298 observed by Raman spectroscopy. In the first approach, the 299 sample was modeled as a $2 \mathrm{D}$ axisymmetric solid containing an 300 oblate spheroidal inclusion. ${ }^{44}$ The stress field around a cavity 301 has been studied many times. In particular, Eshelby ${ }^{45}$ studied 302 how an applied stress, uniform at large distances, is disturbed 303 by a cavity. From this early work, many analytical or closed- 304 form analytical solutions have been proposed for spherical or 305 spheroidal inclusions and considering isotropic or anisotropic 306 materials. ${ }^{46-54}$ The problem becomes more complicated for a 307 spheroidal cavity hosted in an anisotropic solid. On the other 308 hand, FEA has proved its reliability for solving mechanical 309 problems especially in the case of linear elastic problems but 310 also in the case of geometric nonlinearity and with nonlinear 311 isotropic elastic materials. ${ }^{55}$ Actually, FEA can be applied 312 whatever the geometry of the inclusion.

In a first approach, the sample was modeled as a $2 \mathrm{D} 314$ axisymmetric solid containing an oblate spheroidal inclusion, ${ }^{44} 315$ and the finite-element-based results were compared with 316 theoretical results obtained using the code recently developed 317 by Meng et al. ${ }^{51-53}$ which gives quasianalytical strain/stress 318 fields following Eshelby's solution, with the elliptic integral 319 approximated through a numerical routine. The purpose of this 320 comparison was to determine the size of the solid surrounding 321 the cavity to avoid boundary effects and define the meshing 322 strategy to avoid numerical artifacts or errors and to better 323 understand the stress field building around the inclusion. An 324 isotropic elastic material was defined in the solid part with 325 Young's modulus of $100 \mathrm{GPa}$ and Poisson's coefficient of 326 

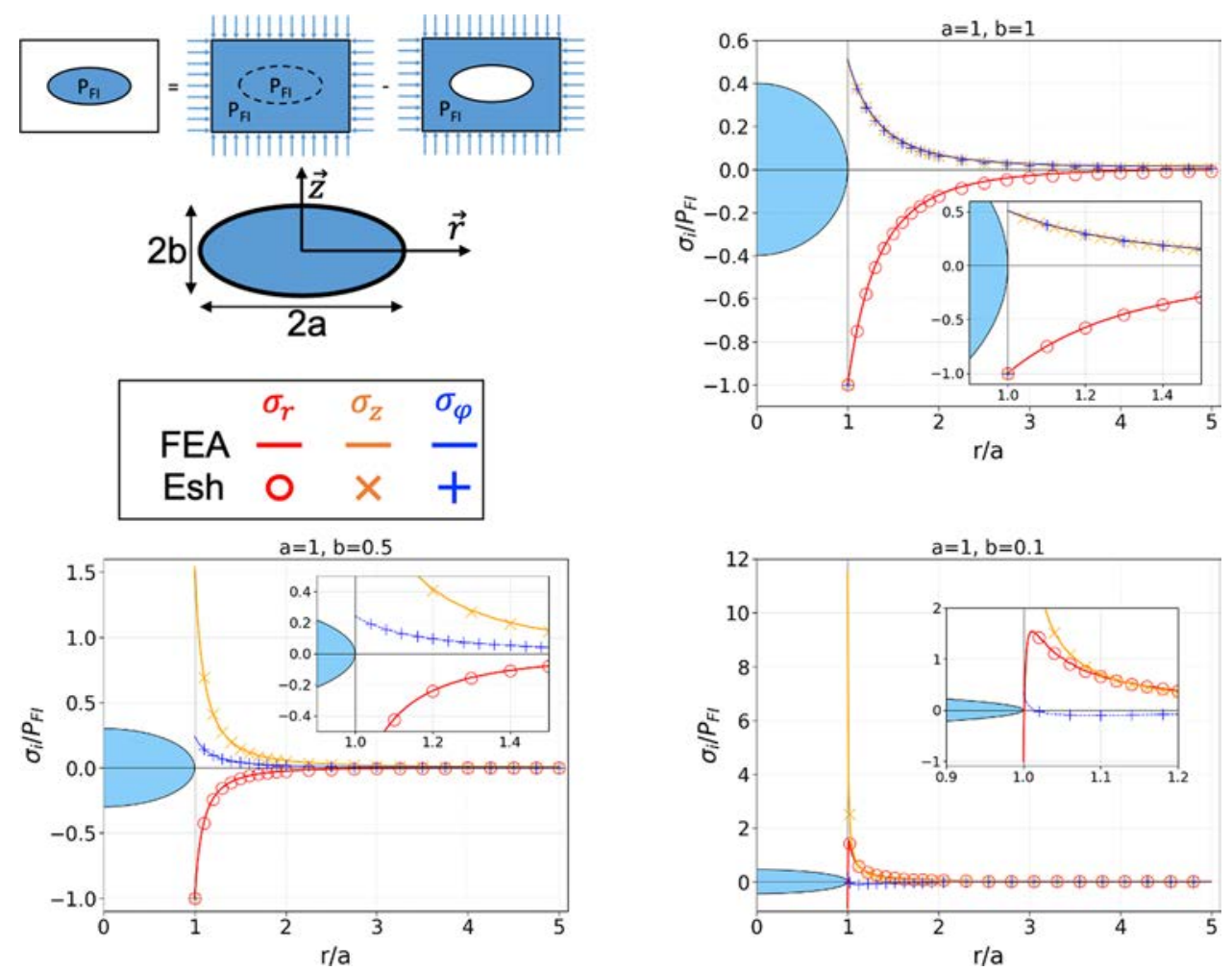

Figure 3. Normalized stress along the radial axis. The normalized stresses are calculated by dividing the stresses by the pressure applied onto the inclusion wall. The normalized radial coordinate is the radial coordinate divided by the half-length of the spheroid, $r^{*}=r / a$. The stresses denoted "Esh" were calculated following Eshelby's theory ${ }^{45}$ by applying script developed by Meng et al. ${ }^{51-53}$ and according to the superposition principle for linear elastic mechanics (top-left of the figure). Stresses that were noted by FEA were calculated using Comsol Multiphysics software. For all the calculations, Young's modulus and Poisson's coefficient were $100 \mathrm{GPa}$ and 0.06 , respectively, according to ref. ${ }^{56}$

$3270.06 .^{56}$ These elastic properties correspond to equivalent quasi328 isotropic quartz obtained by Voigt-Reuss-Hill averaging. ${ }^{56}$ 329 The inclusion was defined with null elastic constants, and a 330 negative pressure $P_{\mathrm{FI}}$ (e.g., $\left.P_{\mathrm{FI}}=-1 \mathrm{MPa}\right)$ was applied on the 331 cavity wall. For the theoretical solution, the superposition 332 principle was applied as the code because it does not directly 333 apply pressure on the cavity wall (Figure 3, top, left). 334 Unstructured triangular quadratic elements were applied for 335 the FEA, and zero displacement was applied to the symmetry 336 plane (horizontal) perpendicular to the revolution axis 337 (vertical). The stresses $\sigma_{\mathrm{ii}} / P_{\mathrm{FI}}$ lying along the radial direction 338 were compared (Figure 3 ). For the sake of simplicity, the stress 339 sign convention commonly used in mechanics has been 340 changed in this paper, and a positive stress refers to a 341 compressive state. The pressure has also been changed $P_{\mathrm{T}}=$ $342 \operatorname{Tr}(\overline{\bar{\sigma}}) / 3$ instead of $P_{\mathrm{T}}=-\operatorname{Tr}(\overline{\bar{\sigma}}) / 3$ to keep its usual meaning, 343 namely, a positive value refers to a compressive state. The 344 stresses were normalized by dividing each of them by $P_{\mathrm{FI}}$ ( $\left.345 \sigma_{\mathrm{ii}}{ }^{*}=\sigma_{\mathrm{ii}} / P_{\mathrm{FI}}\right)$, and the radial coordinate was divided by the half346 length of the ellipse $a\left(r^{*}=r / a\right)$.

347 We considered three shapes defined by the semiaxis ratio $b /$ $348 a$ (hereafter called shape factor), where $a$ and $b$ are the 349 semiaxes in the radial and axial directions, respectively. The 350 third semiaxis $c$ is equal to the radial axis in the oblate 351 spheroid. Simulated results are in very good agreement with 352 theoretical results for all the stresses, proving that the solid 353 model size was large enough and the meshing strategy was 354 suitable. The FEA model was validated. The results show 355 clearly the stress concentration effect induced by the cavity and 356 the dependence of the concentration amplitude on the shape factor $\mathrm{b} / \mathrm{a}$. For a sphere, $b / a=1$, the axial and tangent stresses 357 are equal and compensate the radial stress, and the resulting 358 pressure is null. Each stress does not exceed the pressure, and 359 no stress concentration effect occurs. On the contrary, when 360 the spheroid is flattened, the axial and tangent stresses are not 361 equal any longer, and they do not compensate the radial stress. 362 The axial stress largely predominates the other stresses and 363 reaches up to 12 times the fluid inclusion pressure. The 364 positive values of the axial stress and pressure indicate a 365 compressive state in equatorial plane although a tensile stress is 366 applied on the cavity wall (negative pressure PFI) (Figure 4). $367 \mathrm{f4}$ This effect is due to the flattening of the spheroid and is 368 magnified when the shape factor decreases.

369

Once validated, the ellipsoid-based model was used to 370 simulate the experiments. A negative (tensile) pressure was 371 applied on the 2D elliptical edge to simulate the in-pore 372 pressure change. No gradient or interfacial effects of any sort 373 that may "buffer" the liquid-to-solid pressure transmission were 374 taken into account. The anisotropy of $\alpha$-quartz was considered, 375 and the elastic moduli were defined according to Calderon et 376 al. $^{57}$

Second, the sample was modeled with a $3 \mathrm{D}$ prismatic solid 378 containing a faceted inclusion to look like the inclusion 379 observed with Raman spectroscopy (Figure 5). Only an eighth 380 fs of the sample was modeled considering symmetry conditions, 381 and the dimensions were defined to match the inclusion 382 actually considered. Zero displacement was applied to the 383 three symmetry planes (SP), and a negative pressure was again 384 applied on the inner surfaces of the inclusion. The same 385 


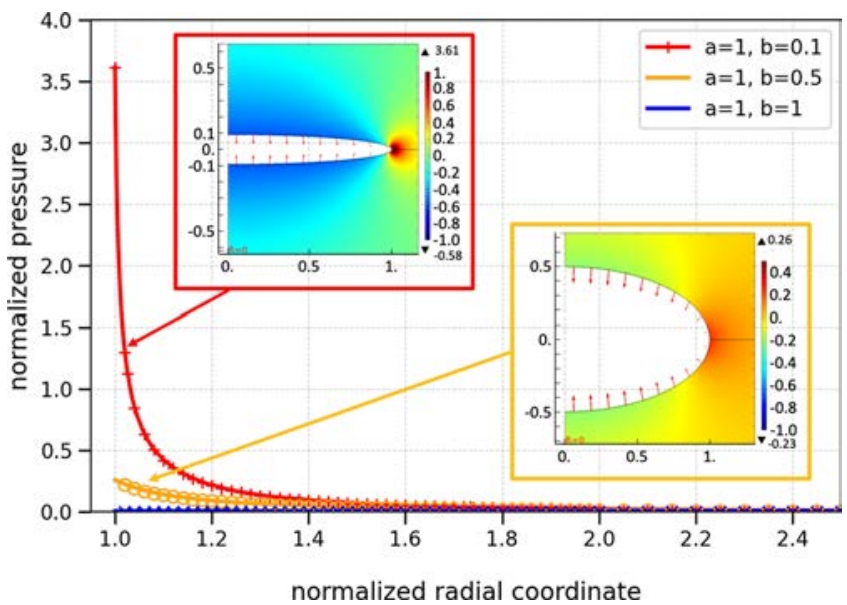

Figure 4. Simulation of a host with a spherical or spheroidal inclusion with a negative (tensile) pressure applied on the wall cavity. See Figure 1 for more details on the model. Normalized pressure simulated with FEA and depending on shape factor b/a, maps, and values along the radial axis. For each shape factor, the continuous line and marks represent the FEA-based pressure and the Eshelby-based pressure, respectively.

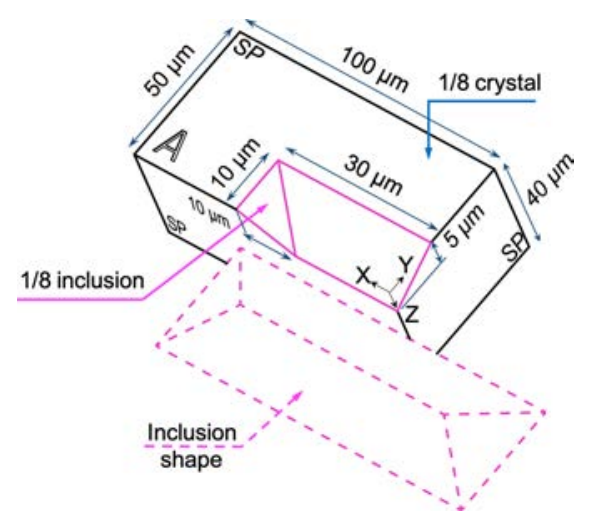

Figure 5. Geometry of the 3D mechanical model of the inclusion for the FEA. Because of symmetries (SP), only an eighth of the solid is modeled. The image size is not scaled with the prism size for visibility purposes.

386 anisotropic elastic moduli as for the previous simulation were 387 used.

\section{EXPERIMENTAL RESULTS AND INTERPRETATION}

$388 \quad$ 3.1. Stressing the Container ( $\mathrm{CsCl}$ Inclusion). The $\mathrm{CsCl}$ 389 fluid inclusion has a $T_{\mathrm{H}}$ of $205.6 \pm 0.4{ }^{\circ} \mathrm{C}$ and $T_{\mathrm{IN}}$ of $89 \pm 1.4$ $390{ }^{\circ} \mathrm{C}$. Drawing a straight line from the synthesis conditions $(630$ $391 \mathrm{MPa}$ and $\left.480{ }^{\circ} \mathrm{C}\right)$ to the $\left(T_{\mathrm{H}} P_{\mathrm{H}}\right)$ pair $\left(\mathrm{d} P / \mathrm{d} T=2.3 \mathrm{MPa} /{ }^{\circ} \mathrm{C}\right)$, 392 and extrapolating this line to the $T_{\mathrm{IN}}$ value, gives the liquid 393 tension existing in the inclusion just before the nucleation, at $394-266 \pm 3 \mathrm{MPa}$ (Figure 6).

395 First, the Raman maps all around a $\mathrm{CsCl}$ inclusion were 396 recorded at $120^{\circ} \mathrm{C}$ while the internal pressure in the liquid was 397 either $0.12 \mathrm{MPa}$, corresponding to biphasic liquid-vapor 398 assemblage, or - $194 \mathrm{MPa}$, corresponding to the metastable 399 monophasic state with liquid under tension. Each mapping 400 took $20 \mathrm{~h}$. The chosen temperature of $120^{\circ} \mathrm{C}$ was sufficiently 401 above the $T_{\mathrm{IN}}$ to avoid any nucleation during the Raman 402 measurement time. Indeed, the metastable lifetime depends 403 exponentially upon the distance to $T_{\mathrm{IN}}{ }^{58-60}$
Two $\mathrm{A}_{1}$ Raman modes of $\mathrm{SiO}_{2}$ with highest wavenumbers 404 were studied: the mode at $464 \mathrm{~cm}^{-1}$ and the mode at 206405 $\mathrm{cm}^{-1}$. The signal was mapped in the quartz around the 406 inclusion (width $70 \mu \mathrm{m} \times$ height $110 \mu \mathrm{m}$ ) that contained the 407 fluid. A G/L profile was fitted with the recorded spectrum at 408 each point, and the characteristic wavenumber of the G/L 409 profile was used to build the map. The map obtained with the 410 $464 \mathrm{~cm}^{-1}$ mode in the stable state (biphasic liquid-vapor 411 assemblage) shows actual wavenumbers ranging from 462.5 to 412 $463.1 \mathrm{~cm}^{-1}$ with a mean value of $462.8 \mathrm{~cm}^{-1}$ (Figure 7). Black $413 \mathrm{f} 7$ spots correspond to regions where the Raman line intensity 414 decreases below a threshold and were used to locate the 415 inclusions. The barycenter of the black spot corresponding to 416 the inclusion of interest was used as the origin of the map. 417 Finally, a micrograph of the inclusion of interest has been 418 superimposed by aligning the lattice directions determined 419 with EBSD with the Raman map with a perfect match. The 420 dark spot is slightly bigger than the inclusion image because of 421 the empirical determination of the threshold.

422

Applying the Schmidt and Ziemann ${ }^{42}$ relation at $120{ }^{\circ} \mathrm{C} 423$ gives an expected wavenumber of $462.4 \mathrm{~cm}^{-1}$, which can 424 favorably be compared with our mean measured wavenumber 425 $462.8 \mathrm{~cm}^{-1}$. Because of uncertainties (absolute calibration of 426 two different spectrometers, accuracy on the wavenumber of a 427 "reference" quartz totally stress-free at RT), these values look 428 similar. Though the wavenumbers of the map seem to follow a 429 rather narrow spread, their spatial distribution is well organized 430 around the inclusion. Four zones aligned with the crystal axes 431 show a remarkable symmetry (Figure 7, left). In the upper and 432 lower triangular zones (where green predominates), the 433 wavenumber is close to $462.75 \mathrm{~cm}^{-1}$ while it is close to 463434 $\mathrm{cm}^{-1}$ in the lateral zones (orange/red pixels). The sharp 435 variation in internal pressure between these domains leads us 436 to think of some localized strains on planar defects, presumably 437 connected with how the inclusion formed (thermal fracturing 438 followed by $\mathrm{SiO}_{2}$ overgrowth).

The map obtained from inclusion in the monophasic state 440 for the same $A_{1}$ Raman mode is presented in Figure 7 on the 441 right. Again, the micrograph of the inclusion of interest has 442 been superimposed. In this figure, the dark spot is hidden by 443 the inclusion image, indicating that the dark spot is smaller 444 than that of the biphasic state map. That is also the case for the 445 other spot located at the bottom-right of each map. This shows 446 that the confocal $\mathrm{z}$ plane slightly changed. The mean 447 wavenumber is $463.0 \mathrm{~cm}^{-1}$, ranging from 462.8 to 463.3448 $\mathrm{cm}^{-1}$. Again, the temperature-corrected wavenumber calcu- 449 lated with the Schmidt and Ziemann ${ }^{42}$ relationship compares 450 favorably with the "monophasic" average value. However, it is 451 the gap between the "biphasic" and "monophasic" values which 452 is of special interest. It is very small $\left(0.25 \mathrm{~cm}^{-1}\right.$ between 462.75453 and $463 \mathrm{~cm}^{-1}$ ), but both measurements were performed on the 454 same spectrometer with the same calibration procedure, and 455 on the same points of one quartz sample. Only the 456 spectrometer stability is involved here. It is worth noting 457 that the color scale for the monophasic state map slightly 458 differs from the LV state one. The color scale of each map has 459 been chosen to emphasize the similarities between the spatial 460 distributions of the colors and consequently of the wave- 461 numbers. Globally, the increase of the Raman wavenumbers of 462 the monophasic state map indicates the development of 463 compressive stress although no optical evidence of quartz 464 failure was recorded during this experiment, which therefore 465 follows a purely elastic behavior. 


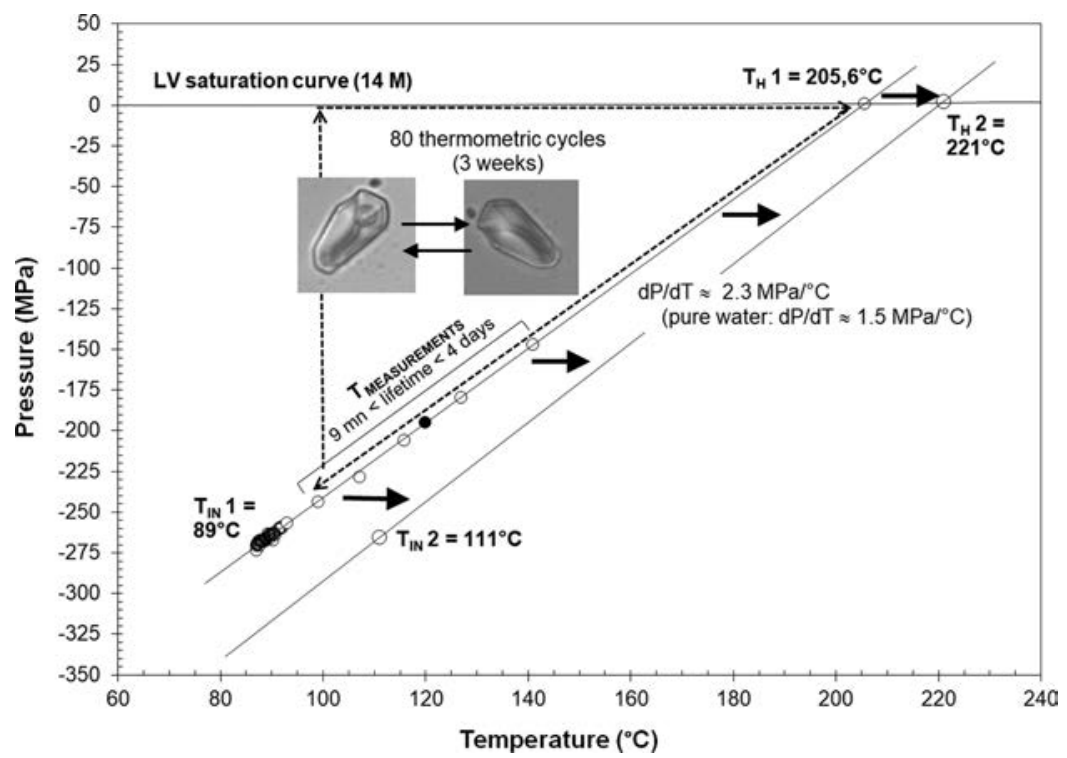

Figure 6. Thermal procedure, microthermometric features, and schematics of the cyclic tension applied to the sample, before (label 1, Section 3.1) and after (label 2, Section 3.2) the stretching irreversible failure of the inclusion.
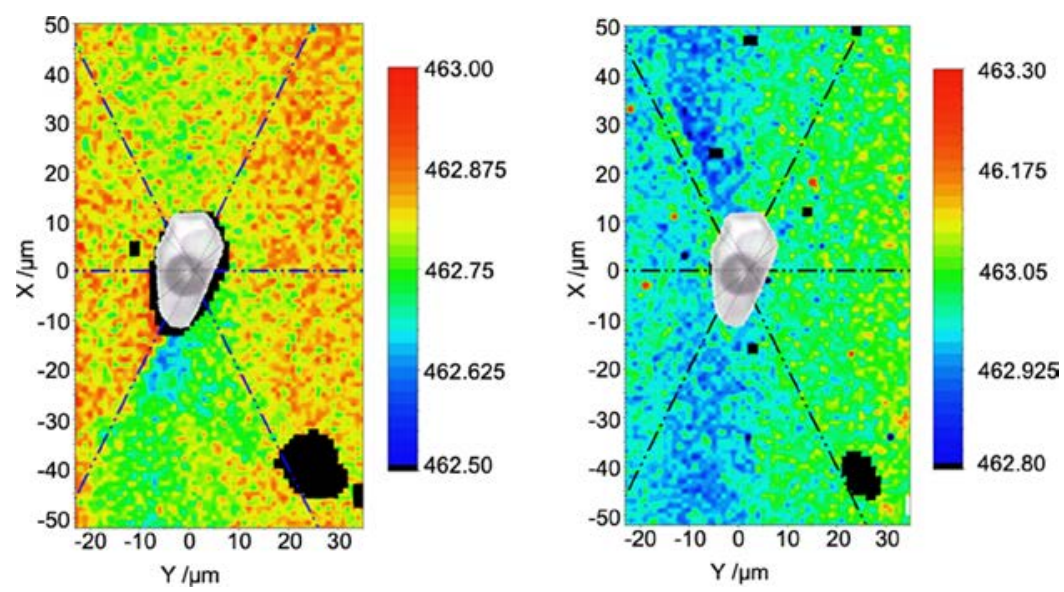

Figure 7. Raman map of the wavenumber of the high wavenumber $A_{1}$ quartz mode, with infilling fluid at the liquid-vapor saturation state (left) and monophasic liquid state (right). The wavenumber values are given by the color scale. The inclusion of interest has been superimposed as well as the crystal axes determined with EBSD.
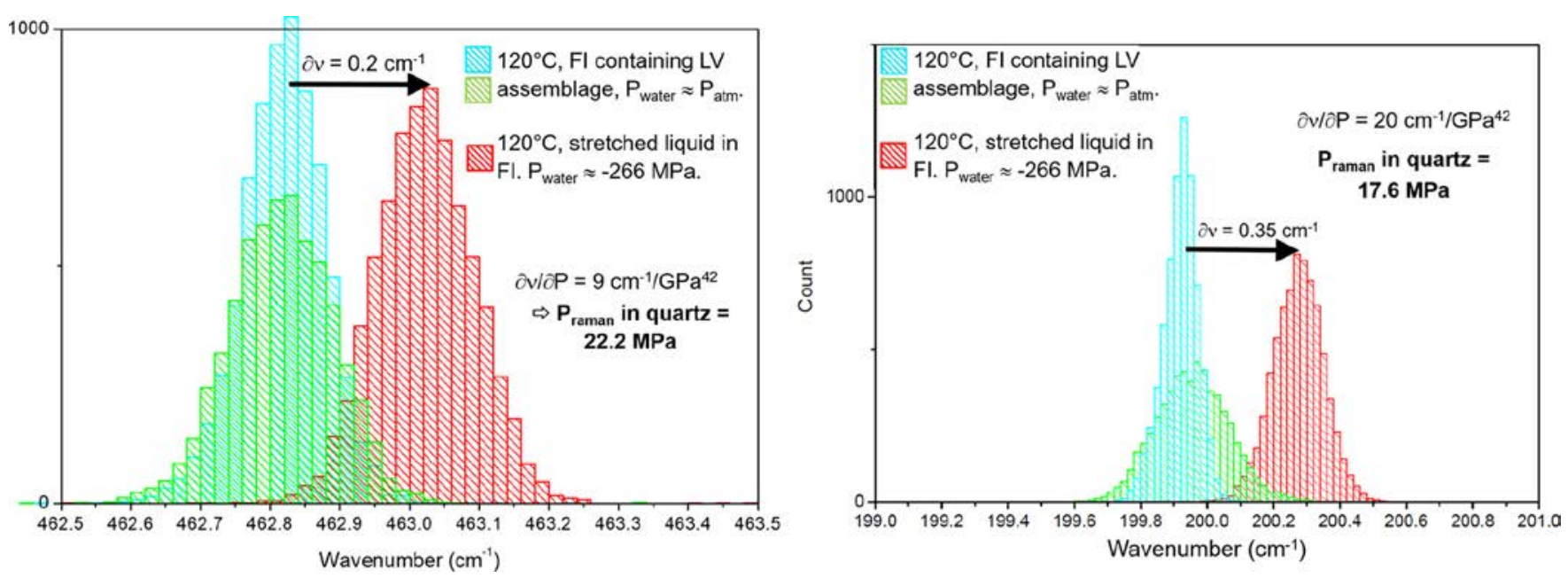

Figure 8. Raman line center histograms at $120{ }^{\circ} \mathrm{C}$ of the 464 (left) and 206 (right) $\mathrm{cm}^{-1}$ bands of quartz around a fluid inclusion filled with either a biphasic liquid-vapor stable mixture (green, blue = repetition to test for reproducibility) or a monophasic tensile liquid (red). 
467 To extract the mean Raman shift provoked by the in-pore 468 tension in the actual sample over the experimental area, the 469 whole data set collected with each map was redrawn as the 470 histogram of the number of occurrences in each wavenumber 471 range, for the two Raman mode maps (464 and $206 \mathrm{~cm}^{-1}$ ) 472 under the two stressed conditions (Figure 8). This shows how 473 the wavenumbers measured vary within the experimental area 474 for the two Raman modes and also shows how regular the 475 datasets are.

476 The liquid-vapor series gives the Raman modes at 477 saturation pressure: the Gaussian maxima are at 462.8 and $478199.9 \mathrm{~cm}^{-1}$. These measurements were double-checked to test 479 the reproducibility of the recorded values (blue and green 480 histograms), and both datasets match well. The match is 481 strictly perfect for the high wavenumber mode (same main 482 wavenumber and same width) while the low wavenumber $A_{1}$ 483 mode gave a $0.015 \mathrm{~cm}^{-1}$ change for wavenumber (showing the 484 high stability of the experiment) with the total width varying 485 by a maximum of $0.1 \mathrm{~cm}^{-1}$. The main information we take 486 from these graphs is the Raman gap that exists between the 487 two $120{ }^{\circ} \mathrm{C}$ datasets at different pressures. Each mode (464 488 and $206 \mathrm{~cm}^{-1}$ ) has a specific gap, quite moderate with respect 489 to the precision of the spectrometer, but largely beyond any 490 instrumental effect. Note that here the key factor of the 491 spectrometer is its stability, not its spectral resolution. Specific 492 care was taken to improve stability by avoiding thermal 493 fluctuations and then any human presence in the experimental 494 room. Now, using the calibration of the Raman shift with 495 pressure, ${ }^{42}$ it is possible to estimate the level of strain involved. 496 The two modes agreed remarkably well for the resulting stress: $49720 \mathrm{MPa} \pm 2.5 \mathrm{MPa}$ (Figure 8). The small difference between 498 the values $\left(22.2 \mathrm{MPa}\right.$ for $464 \mathrm{~cm}^{-1}$ mode and 17.6 for 206 $499 \mathrm{~cm}^{-1}$ mode) can be related to the wavenumber measurement 500 uncertainty, and by the application of only one parameter on a 501 noncubic structure, which is, moreover, not subjected to a 502 hydrostatic pressure but to a complex stress field.

503 The Raman shift difference of the $464 \mathrm{~cm}^{-1}$ mode between 504 the biphasic and monophasic modes was plotted as a map 505 (Figure 9). This plot is a spatial representation of the Raman

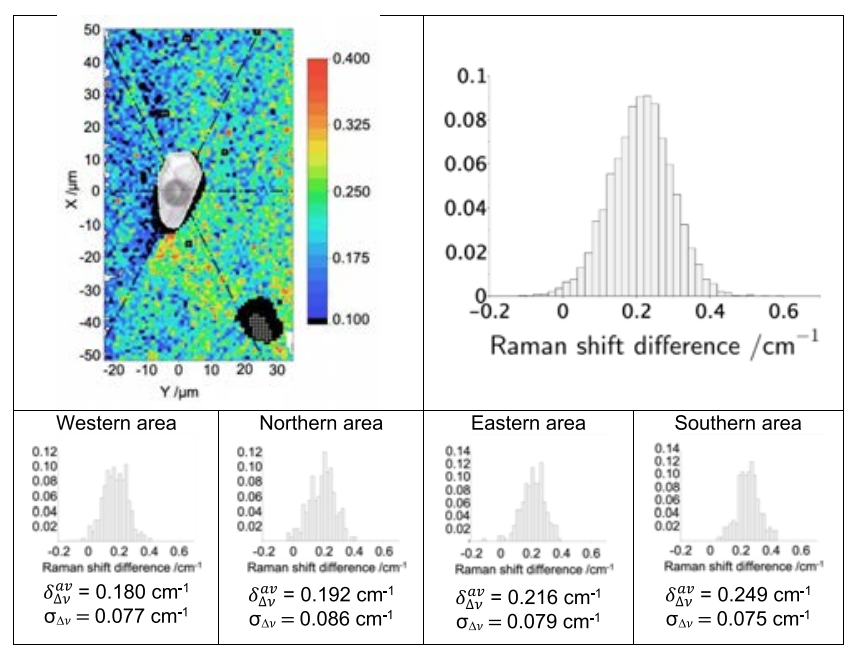

Figure 9. Shift difference between biphasic and monophasic modes for the $464 \mathrm{~cm}^{-1}$ Raman mode. Top-left: Map of the shift difference. Top-right: global histogram of this map. Bottom: Histograms of the four regions indicated by the red rectangles on the map, with a geographic-like denomination. wavenumber change, that is to say the stress distribution 506 induced by the in-pore pressure change. The difference is 507 positive or zero, except for very rare occurrences. In addition, 508 the average wavenumber shift and standard deviation were 509 evaluated in four zones surrounding the inclusion. The area 510 above the inclusion in the map is called "North," and so on. 511 The statistics are very close in the three zones West, North, 512 and East (see Figure 9) with a mean wavenumber shift $\delta_{\Delta \nu}^{\text {av }} 513$ close to the $0.2 \mathrm{~cm}^{-1}$ overall shift (Figure 8) and a very 514 constant standard deviation. This proves that the stress field 515 produced by the in-pore pressure change is superimposed on 516 an initial spatial stress/strain distribution observable in the 517 Raman map under LV conditions (Figure 7, left). The 518 southern zone shows a different behavior with a higher 519 Raman shift difference $\left(0.249 \mathrm{~cm}^{-1}\right)$ corresponding to a 520 Raman pressure of $28 \mathrm{MPa}$. It is worth noting that the highest 521 shift difference represented by the red/orange pixels in Figure 522 9 follows the crystallographic axis.

523

3.2. Nonvisible Failure of the Container $\left(\mathrm{CsCl}_{524}\right.$ Inclusion). The experiment was carried out repeatedly (see 525 Section 2.4 with the cyclical procedure). After around 80 cycles 526 carried out over 3 weeks, with tension lasting from some 527 minutes to some days during each cycle, a brutal change of $T_{\mathrm{H}} 528$ was observed, expressing an internal failure (usually called 529 "inclusion stretching" in the inclusionist's glossary; see ref. ${ }^{61} 530$ for a review about the different types of damage in inclusions) 531 and a change of the cavity volume. $T_{\mathrm{H}}$ was then upshifted by 16532 ${ }^{\circ} \mathrm{C}$, and logically, the $T_{\mathrm{IN}}$ changed by a similar value, at $T_{\mathrm{IN}}=533$ $111{ }^{\circ} \mathrm{C}$ (Figure 6). Despite this thermometric evidence, the 534 change in the cavity shape or volume was so small that it could 535 not be observed optically (this is usual with this "inclusion 536 stretching"), leading us to infer that the volume change 537 resulted from the formation of damage at the microscale as a 538 network around the inclusion, below the optical limit. 539

The Raman maps were then measured at $140{ }^{\circ} \mathrm{C}$, that is to 540 say, for the same $T-T_{\text {IN }}$ difference as for the previous data sets. 541 They showed a very weak Raman shift between the biphasic 542 and the monophasic situations (Figure 10), much weaker than $543 \mathrm{f} 10$ in the precracked state (Figure 8). This fact matches very well 544 with the presence of a dense network of microcracks, 545 diminishing the lattice stress detectable with Raman spectros- 546 copy.

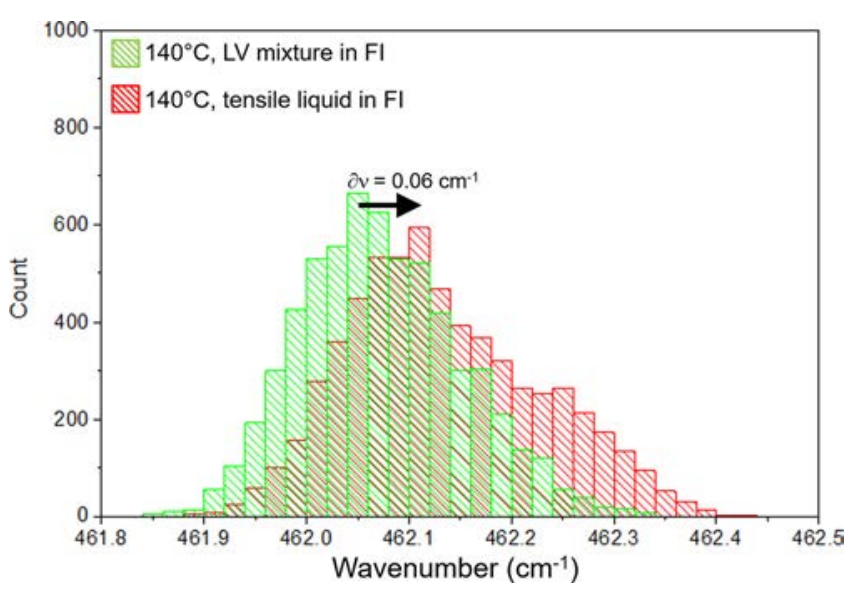

Figure 10. Histograms of the line center of the high wavenumber band, at $140{ }^{\circ} \mathrm{C}$, along the equatorial plane of the inclusion, after the $T_{\mathrm{H}}$-recorded damage. 
548 It means that, despite the low stress thus registered, the 549 cyclical procedure led to a real damage all around the cavity 550 materialized by a brutal increase of $T_{\mathrm{H}}$. The local damage is 551 also evidenced by the Raman maps recorded after the damage 552 of the inclusion, which show much lower values of the peak 553 stress (i.e., for the largest tension in the inclusion), +6.7 MPa 554 (Figure 10), compared to the precracked state (+20 MPa in 555 the plane, Figure 8). This large drop of the in-plane stress is 556 interpreted as the presence of a dense network of microcracks, 557 able to adjust the liquid tensile stress by a multitude of 558 microdisplacements inside the crack, instead of provoking a 559 lattice stress detectable with Raman spectroscopy.

560 3.3. Fracturing the Container ( $\mathrm{NaOH}$ Inclusion). The $561 \mathrm{NaOH}$ sample contains four inclusions shaped as "negative 562 quartz crystals" (Figure 11), numbered 1 to $4 . T_{\mathrm{H}}$ is revolving

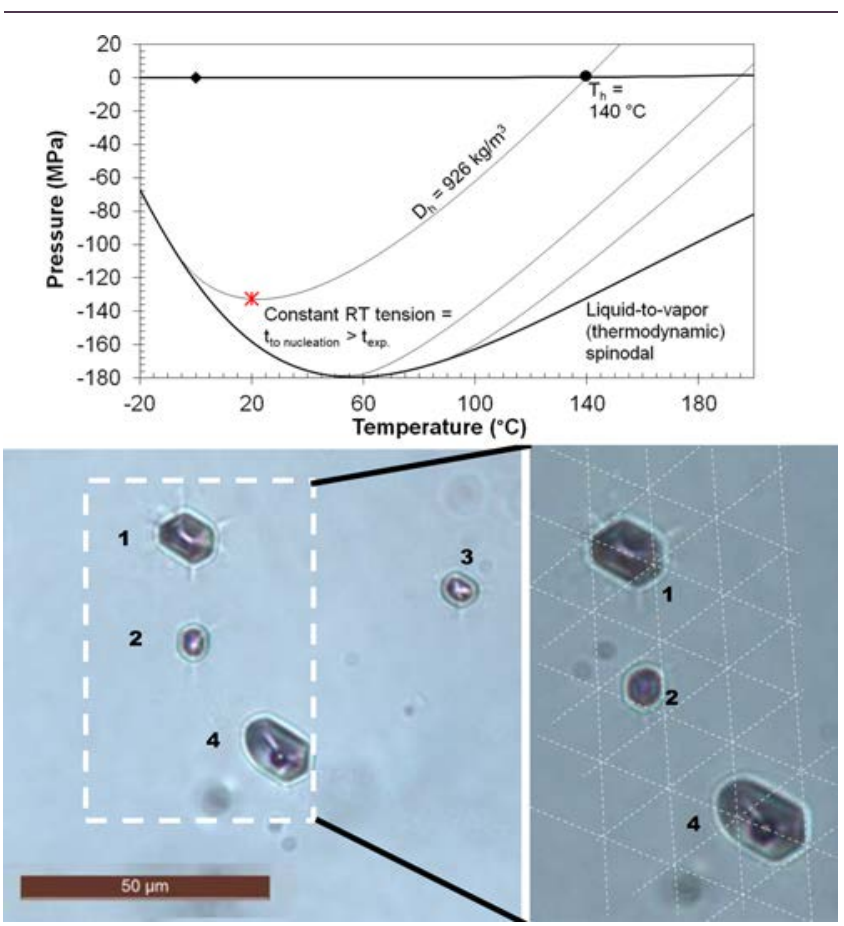

Figure 11. Upper panel, installing the "enduring tension" situation by isochoric cooling of a high-density SFI. Bottom left, observation of three fluid inclusions numbered (1-3) with microcracking in the quartz at each corner of the negatively shaped cavity. The fourth (num. 4), which does not tolerate tensile stress (see the bubble), is intact. Bottom-right, crystallographic axes measured by EBSD are reported on the right micrograph.

563 around $140{ }^{\circ} \mathrm{C}$, corresponding to a mean water density of $D \approx$ $564926 \mathrm{~kg} / \mathrm{m}^{3}$ according to IAPWS EoS (pure water approx565 imation $^{37}$ ) (Figure 11). Inclusions $1-3$ did not show any 566 instantaneous nucleation in the positive (Celsius) temperature 567 area. At RT and after isochoric cooling from $T_{\mathrm{H}}$, the liquid 568 tension in the three monophasic inclusions $1-3$ was -132 $569 \mathrm{MPa}$ (Figure 11). Inclusion 4 had $T_{\mathrm{IN}}$ equal to $44{ }^{\circ} \mathrm{C}$ so this 570 inclusion was never under tension under ambient conditions 571 while the three others were, giving us a "reference" inclusion 572 without a fluid pressure effect on the nearby surroundings.

573 With this RT superheating installed in inclusions $1-3$, we 574 started observing the inclusions subjected to a permanent 575 tension from the in-pore liquid. Surprisingly, after only some 576 weeks and before any Raman records or accumulation of data 577 on the inclusions of interest, the host quartz cracked all around the three inclusions hosting tensile liquid, consistent with the 578 crystallographic axis (Figure 11, bottom-right panel).

The quartz failure occurred with optically visible cracks 580 appearing at the edge of the three inclusions $1-3$. The bright 581 border is underlined by a similar black edge when zooming: 582 the cracks cannot be due to an optical artifact. Inclusion 4, 583 which was never subjected to long tension $\left(T_{\mathrm{IN}}>\mathrm{RT}\right)$, was not 584 damaged. The coexistence between the two mechanical 585 behaviors, so well correlated with the microthermometric 586 features, is a clear indication that the liquid tension is able to 587 fracture the surrounding quartz.

3.4. Numerical Models of Stress Concentration and 589 Fracturing. 3.4.1. Ellipsoidal Model and Pressure in the 590 Equatorial Plane. The simulated stresses and pressure 591 resulting from FEA simulation based on oblate spheroids 592 with a shape factor $b / a=0.1$ are represented in Figure 12. The $593 \mathrm{f} 12$

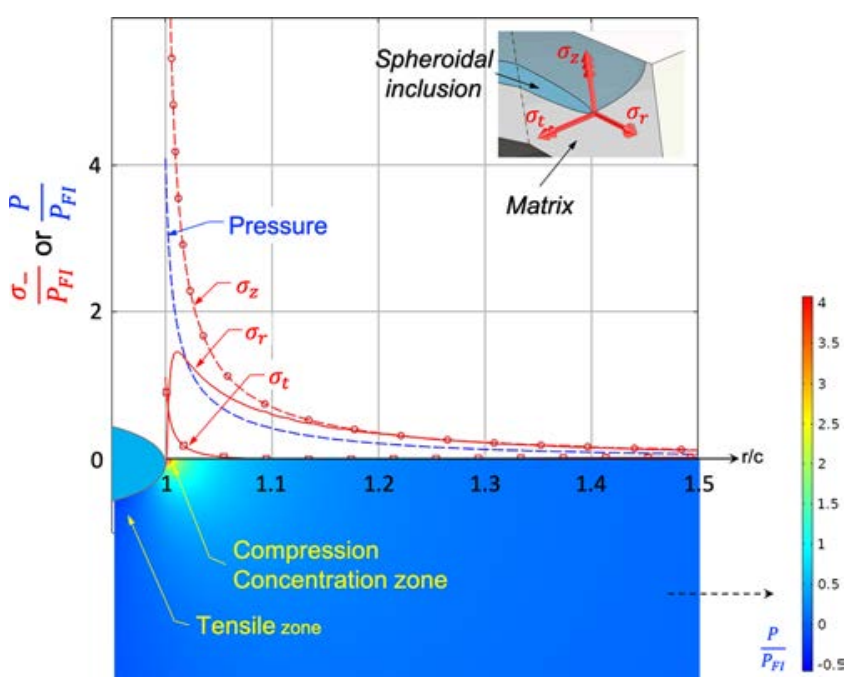

Figure 12. 2D axisymmetric mechanics model of an ellipsoidal-shaped inclusion. Bottom: Normalized pressure map around an inclusion. The vertical symmetry axis is the revolution axis. Top: Stresses and pressure magnitude along the radial axis in the optical plane.

pressure is highly concentrated close to the inclusion edge 594 where it reaches four times the fluid inclusion pressure and 595 decreases sharply along the radial axis. The pressure 596 distribution corroborates the Raman observations (Figure 597 10): a compressive stress (positive) lies within the equatorial 598 plane around the cavity (red color). This can be explained by 599 the flattening of the spheroid, like what occurred with the 600 remote stress above. The simulation indicates that the principal 601 stresses are aligned with the geometrical axes, that is, the radial, 602 tangent, and axial directions of the ellipsoid (see the $r, t$, and $z 603$ directions, respectively, in the inset top-right in Figure 12). In 604 the equatorial plane, the compressive axial stress $\square_{z}$ is the 605 largest contribution to the total pressure while the magnitudes 606 of the tangent and radial stresses $\square_{t}$ and $\square_{r}$ are much smaller. 607 The tangent stress $\sigma_{\mathrm{t}}$ is compressive as well and contributes to 608 a lesser extent to the total pressure. On the other hand, radial 609 stress $\sigma_{\mathrm{r}}$ does not have a monotonous change. It has a negative 610 value in the very vicinity of the edge, quickly inhibited by the 611 global flattening of the inclusion yielding a compressive stress. 612

3.4.2. Real Inclusion Shape and the Stress Concentration 613 in the $\mathrm{CsCl}$ Inclusion. The Raman shift can be evaluated from 614 either from Grüneisen's constant as shown above or from the 615 deformation phonon potentials, usually noted $p, q$, and $r, 616$ 
617 which are the components of the fourth rank tensor relating 618 the changes of the spring constants of the lattice and the 619 deformation tensor. ${ }^{62}$ They generally are determined from 620 hydrostatic pressure Raman experiments using diamond anvil 621 cells, uniaxial stress experiments, or strained thin film grown by 622 strained-layer epitaxy. It is worth noting that the third potential $623 r$ relates the shear strain components of the tensor. Briggs and 624 Ramdas $^{63}$ determined the deformation potential constants of 625 the zone-center optical phonons of $\alpha$-quartz under uniaxial 626 stress experiments. Finally, the Raman shift can also be 627 evaluated from the stresses using the components of the fourth 628 rank elastic tensor relating stress and strain.

629 In the present case, the radial, tangent, and axial stresses are 630 also the principal stresses because of the symmetry of the 631 geometry and the loading, and it is therefore possible to derive 632 the expected Raman shift from either the principal stresses or 633 the radial, tangent, and axial stresses. Here, the constants 634 determined by Briggs and Ramdas ${ }^{63}$ were used to calculate the $635464 \mathrm{~cm}^{-1}$ Raman shift from the stresses considering that the $z$ 636 axis of the model coincides with the crystallographic $c$-axis as 637 shown in Section 2.1:

$$
\delta \nu_{\mathrm{A}_{1,464 \mathrm{~cm}^{-1}}}=0.21 \bullet 10^{-2} \times\left(\sigma_{\mathrm{t}}+\sigma_{\mathrm{r}}\right)+0.38 \bullet 10^{-2} \times \sigma_{\mathrm{z}}
$$

638 where the stresses are in $\mathrm{MPa}$ and $\delta \nu$ in $\mathrm{cm}^{-1}$. The Briggs' 639 potentials were determined with an uncertainty of $\pm 0.02 .10^{-2}$ $640 \mathrm{~cm}^{-1} / \mathrm{MPa}$. Note that they are here positive because of the 641 change in the sign of the stresses. The uncertainty of the 642 Raman shift evaluated from uncertainty propagation depends 643 on the stresses and reaches a maximum value of $0.5 \mathrm{~cm}^{-1}$.

644 The Raman shift was also calculated following the Grüneisen 645 formalism:

$$
\delta \nu_{\mathrm{A}_{1,464 \mathrm{~cm}^{-1}}}=8.7 \bullet 10^{-3} \times P
$$

646 where $P$ is in $\mathrm{MPa}$ and $\delta \nu$ in $\mathrm{cm}^{-1}$.

647 Both Raman shifts were evaluated along with the radial axis 648 (Figure 13). The very good agreement between Briggs and

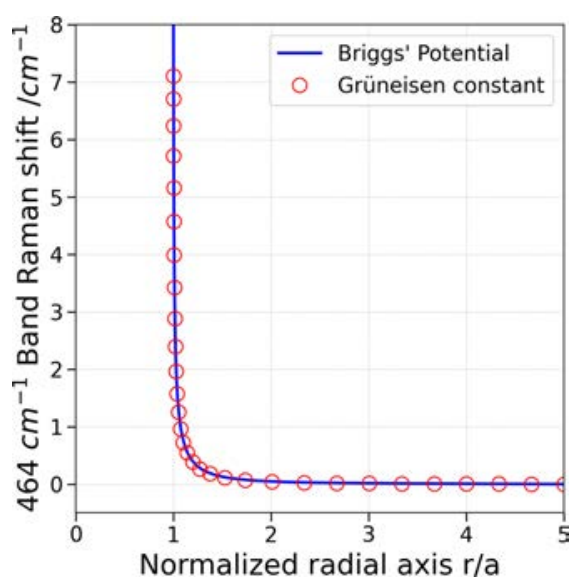

Figure 13. Raman shift evaluation along the radial axis.

649 Grüneisen formalisms confirms that the Grüneisen's constant650 based approach was really reliable in this study, as proposed in 651 Section 2.3.

652 Focusing on the inclusion described in Section 3.1, the 653 Raman pressure at the bottom-right corner of the inclusion 654 (Figure 9) was compared with the simulation of the oblate 655 cavity with a shape factor $\mathrm{b} / \mathrm{a}=0.1$ and anisotropic properties
(Figure 14). The simulated pressure (blue line FEA) quickly $656 \mathrm{f} 14$ tends asymptotically to zero upon moving away from the 657 inclusion, as expected from a direct application of the theory of 658 solid mechanics. In the meantime, the experimental values 659 showed that the sample is under stress over the total area (red 660 stars, Figure 14; see also the green and blue pixels, Figure 9). 661 The pressure derived from the Raman measures shows a slight 662 decrease, especially close to the inclusion (gray area), where 663 the values are in the same order of the simulation. Considering 664 the difficulty in localizing the edge of the Raman map and the 665 assumptions for the Raman pressure calculation and the 666 simplified geometry for the simulation and despite the 667 dispersion of the measured values, measurements and 668 simulation can be estimated as consistent at least from a 669 qualitative point of view. However, the Raman pressure seems 670 to remain constant around $25 \mathrm{MPa}$ when looking over the 671 whole map even farther from the inclusion. This asymptotic 672 mean pressure is not at all expectable and constitutes one of 673 the main surprises of this experimental study. Although we do 674 not have explanations for this bias, it may be compared with 675 the Raman gap averaged over the whole map $\left(0.212 \mathrm{~cm}^{-1}\right.$, i.e., 676 $24 \mathrm{MPa}$ ). Another point to be considered is the presence of 677 another cavity, which might not be alone, close to the studied 678 inclusion. The stress fields induced by these surrounding 679 cavities might produce such a general overstress. Finally, the 680 general overstress may also be related to the localized strain/ 681 stress induced by the inclusion synthesis procedure. 682

The Raman pressure appears to be a good probe of the 683 stress fields around the water-bearing cavity, and a highly 684 resolved measurement of the instantaneous/local stress is 685 certainly possible according to our preliminary results. It is also 686 clear that any change in the in-pore pressure drives a significant 687 modification in the poromechanical stress field, over an 688 unexpected long-range scope. To address these findings, 689 further studies should involve the anisotropic strain prop- 690 agation in the matrix along preferential axes (crystallography, 691 dislocations, etc.) by carefully plotting how the quartz band 692 varies from place to place, at saturation pressure. It was already 693 clear (Figure 7 left) that our hydrothermal monocrystalline 694 quartz was not uniform in terms of Raman shift.

3.4.3. Real Inclusion Shape and the Fracturing of the 696 $\mathrm{NaOH}$ Inclusion. The objective of the FEA simulation 697 performed on the 3D faceted cavity (Figure 5) was to model 698 the fracturing of the $\mathrm{NaOH}$ hexagonal shaped inclusions as a 699 result of tensile liquid in the cavity (Figure 11). As a preamble, 700 it is well known that geometrical singularities yield artificially 701 increased stress in finite elements depending on the meshing. 702 In addition, the real interface between the inclusion and the 703 contained liquid is not as clear as in the geometrical model 704 where the interface corresponds to a wall. Therefore, values of 705 the simulated pressure must be carefully considered. The main 706 purpose is to obtain tendencies that give us a better 707 understanding of crack formation. As expected, the (negative) 708 tensile pressure applied on the inner wall of the cavity (-200 709 $\mathrm{MPa}$ ) yields a tensile state within the major part of the solid 710 domain proved by the negative value of the simulated pressure 711 (Figure 15, left). Like for the oblate spheroid model, the shape $712 \mathrm{f15}$ factor effect is observed as the pressure increase concentrates 713 around the inclusion, reaching positive values along the cavity 714 edges lying in the symmetry plane A, significantly higher than 715 the applied inner pressure and indicating a compressive state in 716 the plane induced by the predominant flattening of the cavity. 717 The pressure reaches its highest values rather in the middle of 718 

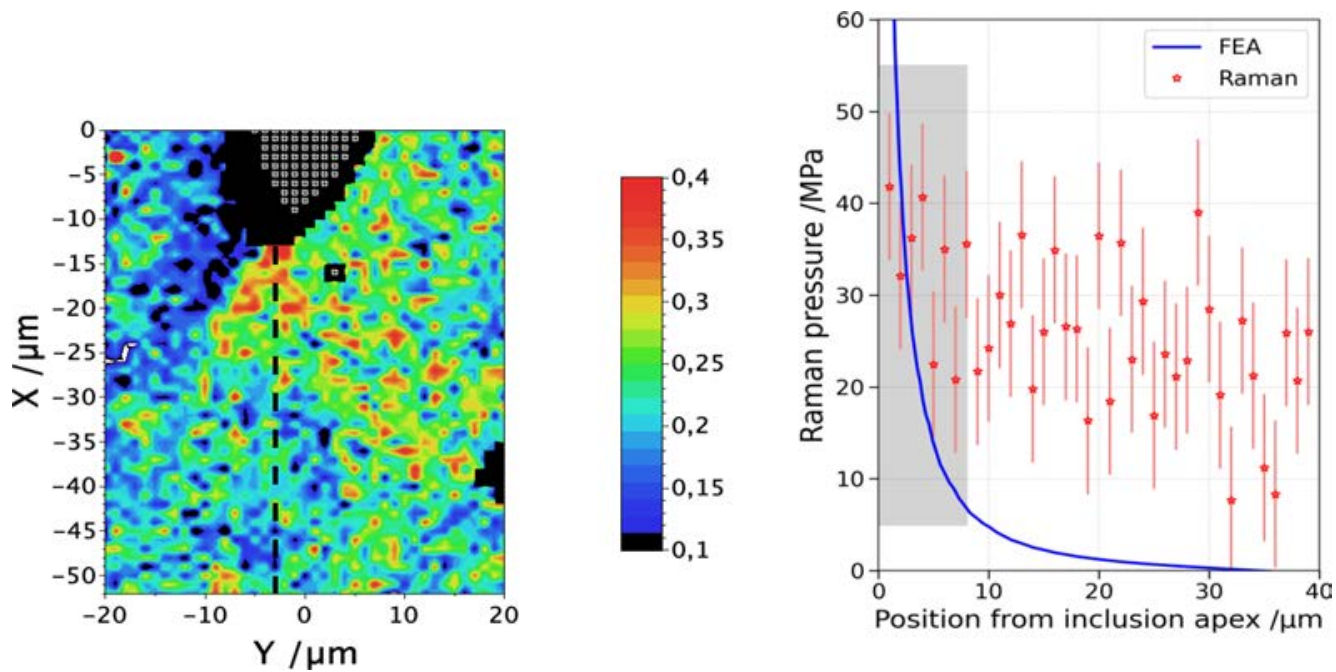

Figure 14. Left, Zooming in the southern area having the larger average wavenumber Raman shift (i.e., Figure 9). Right, Raman pressure (red stars) vs simulation (blue curve). The behavior close to the interface is highlighted as a gray area.
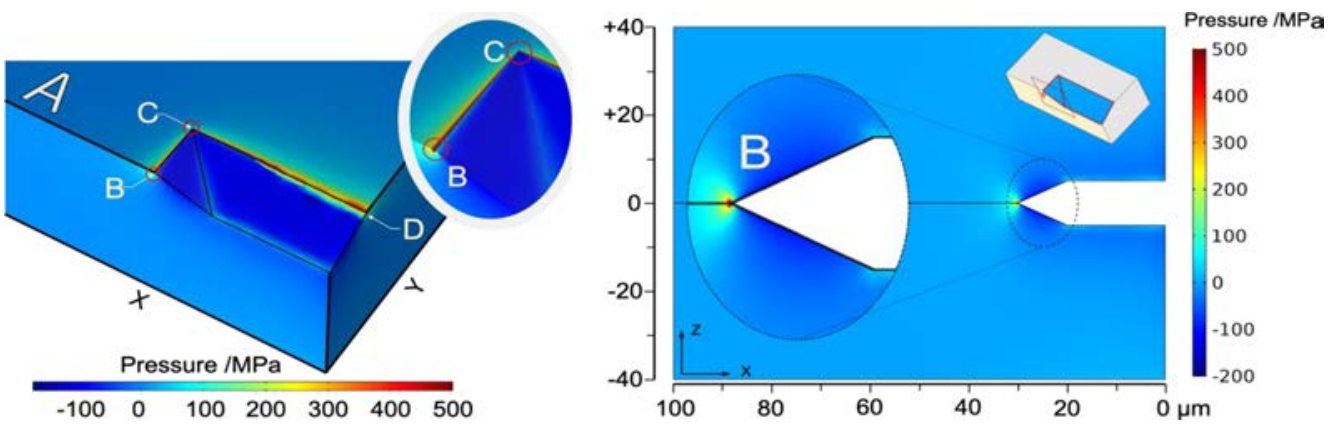

Figure 15. Pressure field showing (left) stress concentration along the longest edge lying in the symmetry plane XY (see Figure 5) near inclusion wall angles and (right) domains of negative/positive stress in the $\mathrm{XZ}$ symmetry plane.

719 the equatorial edges (e.g., points B and D) instead of the apex 720 (e.g., point C) where the cracks form.

721 Focusing on the symmetry plane A (equatorial plane) that 722 contains edges B-C-D of the inclusion, we observe that two 723 principal stresses lie in plane $A$ and that last one is 724 perpendicular to the plane. This can be explained by the 725 geometrical symmetry, quartz trigonal symmetry, and the 726 orientation of the inclusion with respect to the crystallographic 727 axes. The highest compressive stress is perpendicular to the 728 equatorial plane aligned with crystallographic $c \rightarrow$ axis and is 729 very concentrated along the cavity edges (Figure 16). The 730 second compressive stress lies in the equatorial plane with 731 lower magnitude (Figure 16b, compare the color scale with 732 that of Figure 16a). The third principal stress also lies in the 733 equatorial plane and shows negative values corresponding to 734 tensile stress. It reaches its maximum magnitude around the 735 apex $\mathrm{C}$ (Figure 16c, tensile stress). The tensile stress direction 736 being along the line with the same origin and orientation as 737 experimentally observed in the studied inclusions (Figure 11) 738 confirms the possibility of crack formation along this line.

\section{DISCUSSION}

739 4.1. The Raman Pressure. Micro-Raman was here used to 740 dynamically follow the internal pressure in a crystal hosting a 741 variable pore tension. It is assumed that the applicability of the 742 Grüneisen formalism allows us to translate the Raman shift 743 into pressure. The anisotropy of monocrystalline quartz and the imperfections of the crystal lattice even under room 744 conditions (see the Raman "irregularities" in Figure 7 left) 745 limit this applicability. However, our study relies on the 746 comparison of two datasets obtained at two different pore 747 pressures, with all other parameters being constant. In 748 addition, the shift is observed for two different Raman 749 vibration modes, and it is very comparable. In that sense, the 750 recorded Raman shift cannot be related to mechanisms other 751 than lattice deformation and can be interpreted with 752 confidence using the solid's linear elasticity.

Raman microspectrometry of silica minerals is commonly 754 used to determine the pressure conditions of polymineralic 755 assemblages containing various solid inclusions in minerals 756 (e.g., refs ${ }^{64-70}$ ). The dominant compression mechanism is 757 considered to be the reduction of ( $\mathrm{Si}-\mathrm{O}-\mathrm{Si}$ ) (e.g., ref. $^{71}$ ). A 758 similar Raman barometry is used for the $P-T$ conditions of the 759 diamonds' source regions, based on determination of the 760 internal pressure in olivine inclusions and the stresses in the 761 surrounding diamond (e.g., refs. ${ }^{72,73}$ ). More recently, the 762 Raman shifts of sapphires around a zircon inclusion were 763 converted to hydrostatic pressure and deviatoric components 764 of the stress tensor, combining micro-Raman and photo- 765 luminescence imaging techniques, linked by the piezospectro- 766 scopic effects on Raman and photoluminescence spectra. ${ }^{74} 767$ The internal stress was highly concentrated at the tips of the 768 zircon crystal, resulting in a compressive stress of several 769 hundreds of $\mathrm{MPa}$ and leading to most inclusions in radial 770 


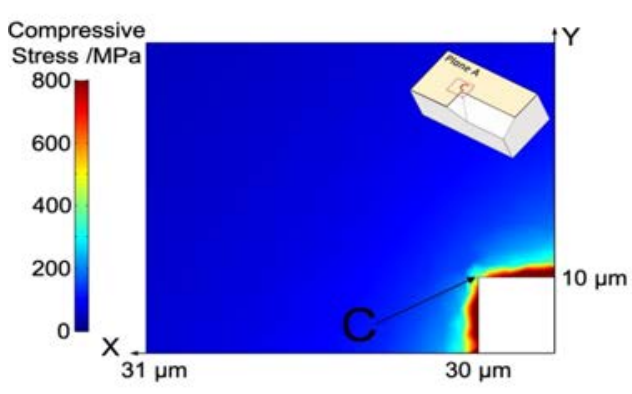

a) Compressive stress orthogonal to the map plane.

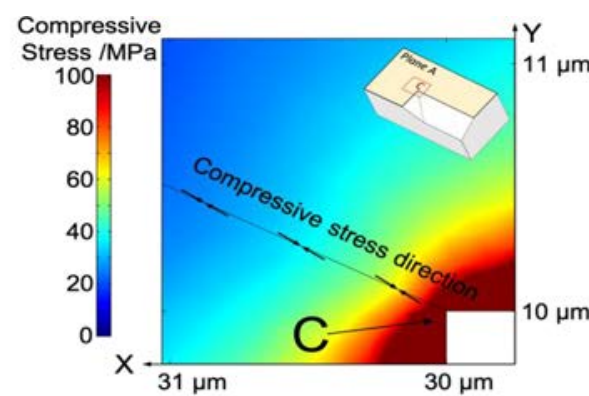

b) Compressive stress lying in the map plane and direction along the straight line of potential fracture.

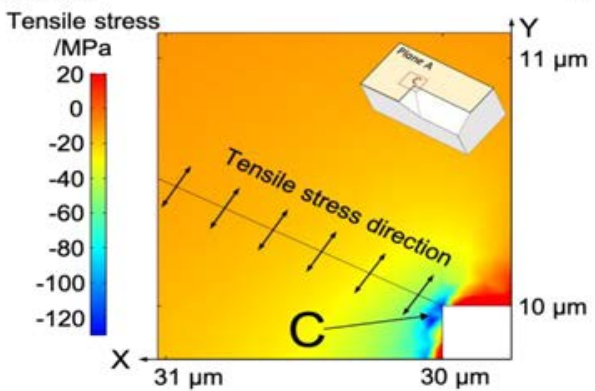

c) Tensile stress map and direction along the straight line of potential fracture.

Figure 16. Principal stress magnitude map near the corner of the symmetry plane XY (see Figure 5, plane noted A). (a) Principal compressive stress $\left(\sigma_{\perp}\right)$ perpendicular to the plane. (b) Second principal compressive stress $\left(\sigma_{\mathrm{II}}\right)$ field near the corner of the symmetry plane XY (Figure 5, plane noted A). The double black arrows indicate the direction of $\sigma_{\mathrm{II}}$ along the line corresponding to the potential crack direction. (c) Principal tensile stress $\left(\sigma_{\mathrm{T}}\right)$ field near the corner of the symmetry plane XY (see Figure 9, plane noted A). The double black arrows indicate the direction of $\sigma_{\mathrm{I}}$ along the line corresponding to the potential crack direction. Note that negative/positive values indicate tensile/compressive stress.

771 cracks propagating in the host sapphire crystal from the apex of 772 the hexagonal zircon. The present paper affords evidence that 773 cracking can be invisible while leading to significant variation 774 of the residual pressure. It could explain the growing 775 observations in natural samples of a wide scattering of residual 776 pressure sealed in inclusions (e.g., refs. ${ }^{75-78}$ ).

777 4.2. Crystal Host Stress Field. The comparison between 778 simulation and Raman measurements is to some extent 779 hindered by the heterogeneity displayed by the sample. 780 When recording the spectroscopic signatures at RT, namely, 781 the reference state without any external constraint, the data set 782 showed significant variations of the Raman peaks across the 783 whole map. Raman peaks showed a distribution into four 784 quadrants, which remained almost unchanged whichever the 785 fluid pressure (Figure 5). These measurements demonstrate 786 that the host crystal is not the perfect, stress-free monocrystal 787 assumed in the simulations. Experiments confirm the idea that 788 the elastic deformations induced by the growing fluid pore 789 tension retain and even magnify the initial imperfections. The 790 Raman maps clearly show that the tension-driven shifts are 791 amplified along the crystallographic axes. Therefore, both the 792 Grüneisen formalism to convert Raman signatures into 793 pressure and a direct comparison of such values to FEA 794 simulations done through isotropic elastic theory can only 795 approximately describe the complex mechanical behavior of 796 quartz.

797 In spite of these limitations, the Raman measurements do 798 retrieve features expected from elastic theory: (i) a 799 compressive stress develops within the equatorial plane and 800 (ii) the stress concentration is maximal in the vicinity of the 801 cavity tip (Figure 14). Furthermore, the shape of the pore 802 cavities plays a role in the stress field to build up a potentially complex 3D result (Figures 15 and 16). This complexity is 803 certainly increased by the pre-existence, before installing any 804 new constraints, of a certain degree of heterogeneity that is 805 visible in the Raman maps at RT (Figure 7 left).

806

4.3. Stress Accumulation and Fracturing Threshold. It 807 is difficult to be quantitative here; however, the stress 808 generated around the water-bearing cavity appears moderate, 809 especially compared to the observations of the damage $\left(T_{\mathrm{H}} 810\right.$ variations, apex fractures) in the host quartz. One proposition 811 for reconciling low stress and evidence of cracking is the role 812 played by fatigue effects in the resistance of materials. Stresses 813 that vary with time and in intensity are able to cause the rock 814 failure while below the yield strength, and even in the linear 815 elastic domain (e.g., refs. ${ }^{5,79-81}$ ). The best illustration is what is 816 known as "reequilibration" in fluid inclusions studies, which is 817 a modification of the inclusion shape and/or a fluid leakage 818 because of the effective stress, namely, the pressure difference 819 between host mineral stress and cavity-filling fluid pressure 820 (e.g., refs ${ }^{82-86}$ ). One strong hypothesis, often claimed to infer 821 various deep fluid conditions from fluid inclusions, is their 822 isochoric behavior along the rock pathway throughout the 823 Earth's crust (burial and/or uplift). To validate it, the 824 resistance of quartz to differential stresses was measured on 825 SFIs for internal under- or overpressure (respectively $P_{\text {solid }}>826$ $P_{\text {fluid }}$ or $\left.P_{\text {solid }}<P_{\text {fluid }}\right)$. Overpressure causes reequilibration from 827 reaching $100 \mathrm{MPa}^{82,85}$ Underpressure caused visible cracks 828 from around $200 \mathrm{MPa}$, while reequilibration proceeded by 829 dissolution-precipitation in the range of 100-200 MPa (e.g., 830 ref. $^{83}$ ). In a later study, cracking was observed when internal 831 underpressure only exceeded $270 \mathrm{MPa}^{85} 832$

In our case, the amplitude of tensile stress in the inclusion, 833 analogous to an underpressure stress, is either $\sim 200 \mathrm{MPa} 834$ 
835 ( $\mathrm{CsCl}$ sample) or $\sim 140 \mathrm{MPa}(\mathrm{NaOH}$ sample). In spite of 836 internal underpressure lower than [82-83]'s, we observed the 837 formation of cracks with the lower differential stress. The 838 simplest explanation for the difference is the effect of confining 839 pressure, absent in our present study, while it is known to 840 inhibit cracking. ${ }^{85}$ An additional effect lies in the geometrical 841 shape of the fluid inclusion, commonly spheroidal for natural 842 inclusions. Our FEA modeling shows that the stress 843 concentration at the tip of the inclusion reached a larger 844 amplitude for the negative crystal shape (as displayed by the 845 SFIs we used) than the spheroidal one. The geometry thus 846 promotes the concentration of stress in the very limited area of 847 the apex, which may facilitate crack initiation.

848 Furthermore, we can speculate a little more about the 849 micromechanical mechanisms that underlie the development 850 of cracks at low levels of tension. For instance, the 851 microprestress theory ${ }^{4}$ offers a comprehensive view of how 852 capillary and disjoining pressures can drive the nucleation and 853 growth of tensile microcracks in the complex pore network of 854 an aging cement. In particular, hindered adsorption inside the 855 nanoscale pores ( 1 to 10 molecular width and 0.3 to $3 \mathrm{~nm}$ ) 856 within hardened cement paste plays a pivotal role. It is 857 appealing to hypothesize, for our experiments, the existence of 858 tiny quantities of water present along the quartz dislocations 859 comparable to the gel pores for cement. The liquid tension 860 existing in the cavity might therefore spread over the nearby 861 crystal lattice owing to minute water-bearing dislocations, 862 propagating the tensile stress farther from the cavity and 863 concentrating the constraints.

\section{CONCLUSION AND PERSPECTIVES}

864 The tension of water occluded in a crystalline cavity has a 865 pore-scale micromechanical effect, as exemplified by the visible 866 cracking for the $\mathrm{NaOH}$ sample, and the microthermometric 867 features change ( $T_{\mathrm{H}}$ increasing) for the $\mathrm{CsCl}$ sample. We 868 demonstrated here that Raman spectroscopy is able to monitor 869 in space and time the pressure in the quartz crystal around a 870 fluid inclusion. The Raman maps revealed that the stress fields 871 induced by the pore tension within the crystalline host rock are 872 nonuniform and concentrated along the crystallographic 873 orientations and, probably, crystal defects. The exact value of 874 stress at these overstressed sites cannot be ascertained by the 875 Raman technique because they may operate at a much smaller 876 scale than the Raman scattering volume. The numerical-model 877 simulated stress field and stress concentration match the 878 measured 3D distribution of stress well and outline the role of 879 geometry in terms of stress concentration in the region where 880 fracturing was observed. On the contrary, the Raman estimates 881 of how stress changes with distance from the inclusion do not 882 match the elastic theory, showing that the crystal defects 883 probably play a role in the stress distribution. Technically, 884 micro-Raman associated with SFI microthermometry appears 885 to be a powerful tool for deciphering the micromechanical 886 mechanisms involved in complex field stress in rocks and 887 porous media.

888 To summarize, our study demonstrates unambiguously that 889 a permanent low stress as well as repeated cyclic stresses 890 established in a crystal lattice by reducing the in-pore pressure 891 in an occluded water-bearing cavity (related to capillary-type 892 effects) is able to damage the hosting quartz despite its high 893 resistance. The mechanical role pressurized pore fluids can play 894 in weakening and embrittling rocks has long been known (e.g., 895 refs. $\left.^{87,88}\right)$, and this paper is a first step in envisioning the role of tensile pore fluids. Furthermore, this result poses the question 896 of the mid/long-term safety of geological storage $\left(\mathrm{CO}_{2}, 897\right.$ nuclear wastes, energy) wherever the geological formations are 898 subjected to drying operations that make it possible to install 899 liquid tension in large masses of unsaturated hydrosystems. In 900 particular, the use of clayey formations to guarantee the 901 confinement of the nuclear species owing to this impermeable 902 barrier must be questioned if the consequent tension of tunnel 903 ventilation was able to enhance permeability in the massif by 904 creating fissures. In the same way, the integrity of the caprocks 905 in $\mathrm{CO}_{2}$ storage is a crucial property that prevents any leakage 906 from occurring. However, the injection of supercritical $\mathrm{CO}_{2} 907$ severely dries out the formation, especially at the highest part 908 where the $\mathrm{CO}_{2}$ bubble accumulates at the very contact with the 909 caprock, establishing the right conditions for tension-driven 910 processes.

During the course of the study, the initiation of micro- 912 cracking and brittle failure was also discussed in association 913 with the water distribution in rock. This aspect is of great 914 significance in natural systems, beyond the question of storage 915 safety. At high pressure and temperature, where deformation 916 proceeds mainly as a result of temperature-dependent viscous 917 creep processes (dislocation- or diffusion creep), fracturing is 918 still present. These brittle precursors promote grain-size 919 reduction and therefore the fluid flow and chemical reactions 920 that activate water corrosion. ${ }^{89-91}$ High fluid pressures, up to 921 confining pressure values, are necessary to open cracks, but the 922 mechanisms are not well understood, even if we know that the 923 physical state of the water present in mineral assemblages with 924 very low porosity is often involved as a triggering 925 mechanism. $^{92,93}$ This study demonstrates that reducing fluid 926 pressure also induces cracking mechanisms rooted at the small 927 scale, even if the generality versus specificity of such 928 mechanisms in the various pressure contexts is still to be 929 explored.

AUTHOR INFORMATION

\section{Corresponding Author}

Lionel Mercury - ISTO, UMR 7327, Univ. Orléans, CNRS, 933 BRGM, Orléans F-45071, France; ๑ orcid.org/0000-0002- 934 3825-663X; Email: lionel.mercury@univ-orleans.fr

\section{Authors}

Emmanuel De Bilbao - CEMHTI, UPR3079 CNRS, Univ. 937 Orléans, Orléans F-45071, France

Patrick Simon - CEMHTI, UPR3079 CNRS, Univ. Orléans, 939 Orléans F-45071, France

Hugues Raimbourg - ISTO, UMR 7327, Univ. Orléans, 941 CNRS, BRGM, Orléans F-45071, France 942

Isabelle Bergonzi - ISTO, UMR 7327, Univ. Orléans, CNRS, 943 BRGM, Orléans F-45071, France

Claudie Hulin - ISTO, UMR 7327, Univ. Orléans, CNRS, 945 BRGM, Orléans F-45071, France 946

Aurélien Canizarès - CEMHTI, UPR3079 CNRS, Univ. 947 Orléans, Orléans F-45071, France

Kirill I. Shmulovich - Institute of Experimental Mineralogy, 949 Russian Academy of Science, Chernogolovka 142432, Russia 950

Complete contact information is available at:

https://pubs.acs.org/10.1021/acsearthspacechem.0c00224

Notes

The authors declare no competing financial interest. 


\section{ACKNOWLEDGMENTS}

956 This work has received financial support from the French 957 Agency for Research (Agence Nationale de la Recherche), 958 through the grant CONGE BLAN-610-01, the Equipex Planex 959 ANR-11-EQPX-36 and the Labex Voltaire ANR-10-LABX960 100-01. The authors are indebted to R. Bodnar, X. Zhong, and 961 a third reviewer for their positive and detailed criticisms which 962 improved the initial manuscript. The English language was also 963 improved by K. Tkaczyk, from McMillan translations. The 964 authors warmly thank Dr. C. Meng for sharing and adapting 965 his scripts for Eshelby theory-based calculations.

\section{$966 \square$ REFERENCES}

967 (1) Eppes, M.-C.; Keanini, R. Mechanical weathering and rock 968 erosion by climate-dependent subcritical cracking. Rev. Geophys. 2017, 969 55, 470-508.

970 (2) Anderson, S. P. Breaking it down: mechanical processes in the 971 weathering engine. Elements 2019, 15, 247-252.

972 (3) Van Eeckhout, E. M. The Mechanisms of Strength Reduction 973 due to Moisture in Coal Mine Shales. Int. J. Rock Mech. Min. Sci. 974 Geomech. Abstr. 1976, 13, 61-67.

975 (4) Bažant, Z. P.; Hauggaard, A. E.; Baweja, S.; Ulm, F.-J. 976 Microprestress-solidification theory for concrete creep. I: aging and 977 drying effects. J. Eng. Mech. 1997, 123, 1188-1194.

978 (5) Atkinson, B. K. Subcritical crack growth in geological materials. J. 979 Geophys. Res. 1984, 89, 4077-4114.

980 (6) Scherer, G. W. Crack-tip stress in gels. J. Non-Cryst. Solids 1992, 981 144, 210-216.

982 (7) Dufresne, E. R.; Corwin, E. I.; Greenblatt, N. A.; Ashmore, J.; 983 Wang, D. Y.; Dinsmore, A. D.; Cheng, J. X.; Xie, X. S.; Hutchinson, J. 984 W.; Weitz, D. A. Flow and fracture in drying nanoparticle suspensions. 985 Phys. Rev. Lett. 2003, 91, 224501. 4 pages

986 (8) Lee, W. P.; Routh, A. F. Why do drying films crack? Langmuir 987 2004, 20, 9885-9888.

988 (9) Bažant, Z. P. Thermodynamics of hindered adsorption and its 989 implications for hardened cement paste and concrete. Cement Concrete 990 Res. 1972, 2, 1-16.

991 (10) Bažant, Z. P.; Wu, S. T. Creep and shrinkage law of concrete at 992 variable humidity. J. Eng. Mech. Div. ASCE 1974, 18, 1183-1120.

993 (11) Coussy, O.; Dangla, P.; Lassabatère, T.; Baroghel-Bouny, V. 994 The equivalent pore pressure and the swelling and shrinkage of 995 cement-based materials. Mater. Struct. 2004, 37, 15-20.

996 (12) Lagier, F.; Jourdain, X.; De Sa, C.; Benboudjema, F.; Colliat, J. 997 B. Numerical strategies for prediction of drying cracks in 998 heterogeneous materials: Comparison upon experimental results. 999 Eng. Struct. 2011, 33, 920-931.

1000 (13) Li, Y.; Li, J. Capillary tension theory for prediction of early 1001 autogenous shrinkage of self-consolidating concrete. Construct. Build. 1002 Mater. 2014, 53, 511-516.

1003 (14) Scherer, G. W. Drying, Shrinkage, and Cracking of 1004 Cementitious Materials. Transp. Porous Media 2015, 110, 311-331. 1005 (15) Charlier, R.; Collin, F.; Pardoen, B.; Talandier, J.; Radu, J. P.; 1006 Gerard, P. An unsaturated hydro-mechanical modelling of two in-situ 1007 experiments in Callovo-Oxfordian argillite. Eng. Geol. 2013, 165, 46100863.

1009 (16) Armand, G.; Noiret, A.; Zghondi, J.; Seyedi, D. M. Short- and 1010 long-term behaviors of drifts in the Callovo-Oxfordian claystone at the 1011 Meuse/Haute-Marne Underground research Laboratory. J. Rock 1012 Mech. Geotech. Eng. 2013, 5, 221-230.

1013 (17) Vinsot, A.; Leveau, F.; Bouchet, A.; Arnould, A. Oxidation front 1014 and oxygen transfer in the fractured zone surrounding the Meuse/ 1015 Haute-Marne URL drifts in the Callovian-Oxfordian argillaceous 1016 rock. In Clays in Natural and Engineered Barriers for Radioactive Waste 1017 Confinement (Norris, S.; Bruno, J.; Cathelineau, M.; Delage, P.; 1018 Fairhurst, C.; Gaucher, E.C.; Höhn, E. H.; Kalinichev, A.; Lalieux, P.; 1019 Sellin, P., editors). Geological Society, London, Special Publications $10202014,400,207-220$.
(18) Vinsot, A.; Linard, Y.; Lundy, M.; Necib, S.; Wechner, S. 1021 Insights on desaturation processes based on the chemistry of seepage 1022 water from boreholes in the Callovo-Oxfordian argillaceous rock. 1023 Procedia Earth Planet. Sci. 2013, 7, 871-874.

(19) Pardoen, B.; Talandier, J.; Colin, F. Permeability evolution and 1025 water transfer in the excavation damaged zone of a ventilated gallery. 1026 Int. J. Rock Mech. Mining Sci. 2016, 85, 192-208.

1027

(20) Vinsot, A.; Lundy, M.; Linard, Y. $\mathrm{O}_{2}$ Consumption and $\mathrm{CO}_{2} 1028$ Production at Callovian-oxfordian Rock Surfaces. Procedia Earth 1029 Planet. Sci. 2017, 17, 562-565.

1030

(21) Osselin, F.; Fen-Chong, T.; Fabbri, A.; Lassin, A.; Pereira, J.- 1031 M.; Dangla, P. Dependence on injection temperature and on aquifer's 1032 petrophysical properties of the local stress applying on the pore wall 1033 of a crystallized pore in the context of $\mathrm{CO}_{2}$ storage in deep saline 1034 aquifers. Eur. Phys. J. Appl. Phys. 2013, 64, 2110110 pages. 1035 (22) Peysson, Y.; André, L.; Azaroual, M. Well injectivity during 1036 $\mathrm{CO}_{2}$ storage operations in deep saline aquifers- Part 1: Experimental 1037 investigation of drying effects, salt precipitation and capillary forces. 1038 Int. J. Greenhouse Gas Control 2014, 22, 291-300. 1039

(23) Ott, H.; Andrew, M.; Snippe, J.; Blunt, M. J. Microscale solute 1040 transport and precipitation in complex rock during drying. Geophys. 1041 Res. Lett. 2015, 41, 8369-8376.

1042

(24) Turuntaev, S.; Merchaeva, O.; Zenchenko, E. Formation 1043 fracturing by pore pressure drop (laboratory study). In ISRM 1044 International Conference for Effective and Sustainable Hydraulic 1045 Fracturing. International Society for Rock Mechanics and Rock 1046 Engineering, 2013, Chap. 51, 993-1011. DOI: 10.5772/56303. 1047

(25) David, C.; Dautriat, J.; Sarout, J.; Delle Piane, C.; Menendez, 1048 B.; Macault, R.; Bertauld, D. Mechanical instability induced by water 1049 weakening in laboratory fluid injection tests. J. Geophys. Res. Solid 1050 Earth 2015, 120, 4171-4188.

1051

(26) Røyne, A.; Meakin, P.; Malthe-Sørenssen, A.; Jamtveit, B.; 1052 Dysthe, D. K. Crack propagation driven by crystal growth. EPL 2011, 1053 96, 24003. 6 pages

1054

(27) Green, J. L.; Durben, D. J.; Wolf, G. H.; Angell, C. A. Water 1055 and solutions at negative pressure: Raman spectroscopic study to -801056 Megapascals. Science 1990, 249, 649-652.

1057

(28) Zheng, Q.; Durben, D. J.; Wolf, G. H.; Angell, C. A. Liquids at 1058 large negative pressures: water at the homogeneous nucleation limit. 1059 Science 1991, 254, 829-832.

1060

(29) Alvarenga, A. D.; Grimsditch, M.; Bodnar, R. J. Elastic 1061 properties of water under negative pressures. J. Chem. Phys. 1993, 98, 1062 8392-8396.

1063

(30) Shmulovich, K.; Mercury, L.; Thiéry, R.; Ramboz, C.; El Mekki, 1064 M. Experimental superheating of water and aqueous solutions. 1065 Geochim. Cosmochim. Acta 2009, 73, 2457-2470.

1066

(31) Fall, A.; Rimstidt, J. D.; Bodnar, R. J. The effect of fluid 1067 inclusion size on determination of homogenization temperature and 1068 density of liquid-rich aqueous inclusions. Am. Mineral. 2009, 94, 1069 1569-1579.

1070

(32) Holmes, H. F.; Mesmer, R. E. Thermodynamic properties of 1071 aqueous solutions of the alkali metal chlorides to $250^{\circ} \mathrm{C}$. J. Phys. 1072 Chem. 1983, 87, 1242-1255.

1073

(33) Roedder, E. Metastable superheated ice in liquid-water 1074 inclusions under high negative pressure. Science 1967, 155, 1413- 1075 1417.

1076

(34) Qiu, C.; Krüger, Y.; Wilke, M.; Marti, D.; Rička, J.; Frenz, M. 1077 Exploration of the phase diagram of liquid water in the low 1078 temperature metastable region using synthetic fluid inclusion. Phys. 1079 Chem. Chem. Phys. 2016, 18, 28227-28241.

1080

(35) Henderson, S. J.; Speedy, R. J. Melting Temperature of Ice at 1081 Positive and Negative Pressures. J. Phys. Chem. 1987, 91, 3069-3072. 1082

(36) Barrow, M. S.; Williams, P. R.; Chan, H.-H.; Dore, J. C.; 1083 Bellissent-Funel, M.-C. Studies of cavitation and ice nucleation in 1084 'doubly-metastable' water: time-lapse photography and neutron 1085 diffraction. Phys. Chem. Chem. Phys. 2012, 14, 13255-13261. 1086

(37) Wagner, W.; Pruss, A. The IAPWS Formulation 1995 for the 1087 Thermodynamic Properties of Ordinary Water Substance for General 1088 and Scientific Use. J. Phys. Chem. Ref. Data 2002, 31, 387-535. 1089 
1090 (38) Marti, D.; Krüger, Y.; Fleitmann, D.; Frenz, M.; Ricka, J. The 1091 effect of surface tension on liquid-gas equilibria in isochoric systems 1092 and its application to fluid inclusions. Fluid Phase Equilib. 2012, 314, 1093 13-21.

1094 (39) Mercury, L.; Shmulovich, K. I.; Bergonzi, I.; Canizares, A.; 1095 Simon, P. Growing negative pressure in fluid inclusions: Raman 1096 monitoring of solvent-pulling effect. J. Phys. Chem. C 2016, 120, 1097 7697-7704.

1098 (40) Parlinsky, K. Ab initio determination of anharmonic phonon 1099 peaks. Phys. Rev. B 2018, 98, No. 054305.

1100 (41) Le Parc, R.; Buixaderas, E.; Levelut, C.; Hermet, P.; Pereira, A. 1101 S.; Cambon, O.; Roiland, C.; Simon, P.; Haines, J. Ultrastable phonon 1102 frequencies in $\alpha$-quartz-type BPO4 at high temperature. Appl. Phys. 1103 Lett. 2019, 115, No. 141902.

1104 (42) Schmidt, C.; Ziemann, M. A. In-situ Raman spectroscopy of 1105 quartz: A pressure sensor for hydrothermal diamond-anvil cell 1106 experiments at elevated temperatures. Am. Mineral. 2000, 85, 1107 1725-1734.

1108 (43) Gregora, I.; Magneron, N.; Simon, P.; Luspin, Y.; Raimboux, 1109 N.; Philippot, E. Raman Study of AlPO4 Berlinite at the Alpha-Beta 1110 Transition. J. Phys. Condens. Matter 2003, 15, 4487-4501.

1111 (44) Healy, D. Elastic field in 3D due to a spheroidal inclusion: 1112 MATLAB code for Eshelby's solution. Comput. Geosci. 2009, 35, $11132170-2173$.

1114 (45) Eshelby, J. D.; Peierls, R. E. The determination of the elastic 1115 field of an ellipsoidal inclusion, and related problems. Proc. R. Soc. 1116 Lond. A 1957, 241, 376-396.

1117 (46) Mura, T.; Jasiuk, I.; Tsuchida, B. The stress field of a sliding 1118 inclusion. Int. J. Solids Struct. 1985, 21, 1165-1179.

1119 (47) Mura, T. Micromechanics of Defects in Solids. Springer 1120 Netherlands. 1987.

1121 (48) Lee, M.; Jasiuk, I.; Tsuchida, E. The Sliding Circular Inclusion 1122 in an Elastic Half-Plane. J. Appl. Mech. 1992, 59, S57-S64.

1123 (49) Pukánszky, B.; Vörös, G. Stress distribution around inclusions, 1124 interaction, and mechanical properties of particulate-filled composites. 1125 Polym. Compos. 1996, 17, 384-392.

1126 (50) Fialko, Y.; Khazan, Y.; Simons, M. Deformation due to a 1127 pressurized horizontal circular crack in an elastic half-space, with 1128 applications to volcano geodesy. Geophys. J. Int. 2001, 146, 181-190. 1129 (51) Meng, C. Esh3D, an Analytical and Numerical Hybrid Code for 1130 Full Space and Half-Space Eshelby's Inclusion Problems. Earth Space 1131 Sci. 2019, 6, 505-514.

1132 (52) Meng, C. Extending Esh3D Code to Solve Interacting Eshelby's 1133 Inhomogeneity Problems. Earth Space Sci. 2019, 6, 1569-1577.

1134 (53) Meng, C.; Heltsley, W.; Pollard, D. Evaluation of the Eshelby 1135 Solution for the Ellipsoidal Inclusion and Heterogeneity. Comput. 1136 Geosci. 2012, 40, 40-48.

1137 (54) Zhong, X.; Dabrowski, M.; Jamtveit, B. Analytical solution for 1138 the stress field in elastic half-space with a spherical pressurized cavity 1139 or inclusion containing eigenstrain. Geophys. J. Int. 2019, 216, 110011401115

1141 (55) Zienkievicz, O.C.; Taylor, R.L. The finite element method for 1142 solid and structural mechanics. Elsevier Butterworth-Heinemann, 2005, 1143632.

1144 (56) Heyliger, P.; Ledbetter, H.; Kim, S. Elastic constants of natural 1145 quartz. J. Acoust. Soc. Am. 2003, 114, 644-650.

1146 (57) Calderon, E.; Gauthier, M.; Decremps, F.; Hamel, G.; Syfosse, 1147 G.; Polian, A. Complete determination of the elastic moduli of $\alpha$ 1148 quartz under hydrostatic pressure up to $1 \mathrm{GPa}$ : an ultrasonic study. $J$. 1149 Phys.: Condens. Matter 2007, 19, No. 436228.

1150 (58) Takahashi, M.; Izawa, E.; Etou, J.; Ohtani, T. Kinetic 1151 characteristic of bubble nucleation in superheated water using fluid 1152 inclusions. J. Phys. Soc. Jpn. 2002, 71, 2174-2177.

1153 (59) Bouzid, M.; Mercury, L.; Lassin, A.; Matray, J.-M. Salt 1154 precipitation and trapped liquid cavitation in micrometric capillary 1155 tubes. J. Colloid Interf. Sci. 2011, 360, 768-776.

1156 (60) El Mekki, M.; Ramboz, C.; Lenain, J.-F.; Caupin, F. A coherent 1157 picture of water at extreme negative pressure. Nat. Phys. 2013, 9, 38115841.
(61) Bodnar, R. J.; Bethke, P. M. Systematics of stretching of fluid 1159 inclusions. I. Fluorite and sphalerite at 1 atmosphere confining 1160 pressure. Economic Geol. 1984, 79, 141-161.

1161

(62) Anastassakis, E.; Pinczuk, A.; Burstein, E.; Pollak, F. H.; 1162 Cardona, M. Effect of static uniaxial stress on the Raman spectrum of 1163 silicon. Solid State Commun. 1970, 8, 133-138. 1164

(63) Briggs, R. J.; Ramdas, A. K. Piezospectroscopy of the Raman 1165 spectrum of -quartz. Phys. Rev. B 1977, 16, 3815-3826. 1166

(64) Hemley, R.J. Pressure dependence of Raman spectra of $\mathrm{SiO}_{2} 1167$ polymorphs: -quartz, coesite and stishovite. In High pressure research 1168 in mineral physics (Manghani, M.H; Syono, Y. Eds), 1987, 347-359. 1169 American Geophysical Union, Washington, D.C.

1170

(65) Ye, K.; Liou, J.-B.; Vong, B.; Maruyama, S. Overpressures 1171 induced by coesite-quartz transition in zircon. Am. Mineral. 2001, 86, 1172 $1151-1155$.

1173

(66) Korsakov, A. V.; Hutsebaut, D.; Theunissen, K.; Vandenabeele, 1174 P.; Stepanov, A. S. Raman mapping of coesite inclusions in garnet 1175 from the Kokchetav Massif (Northern Kazakhstan). Spectrochim. Acta 1176 Part A 2007, 68, 1046-1052.

1177

(67) Ashley, K.; Caddick, M.; Steele-MacInnis, M.; Bodnar, R. J.; 1178 Dragovic, B. Geothermobarometric history of subduction recorded by 1179 quartz inclusions in garnet. Geochem. Geophys. Geosyst. 2014, 15, 1180 $350-360$.

1181

(68) Ashley, K. T.; Darling, R. S.; Bodnar, R. J.; Law, R. D. 1182 Significance of "stretched" mineral inclusions for reconstructing P-T 1183 exhumation history. Contrib. Mineral. Petrol. 2015, 169, 9. (69) Ashley, K. T.; Steele-MacInnis, M.; Bodnar, R. J.; Darling, R. S. 1185 Quartz-in-garnet inclusion barometry under fire: Reducing uncer- 1186 tainty from model estimates. Geology 2016, 44, 699-702. 1187 (70) Cisneros, M.; Ashley, K. T.; Bodnar, R. J. Evaluation and 1188 application of the quartz-inclusions in epidote mineral barometer. Am. 1189 Mineral. 2020, 105, 1140-1151.

1190

(71) Parkinson, C. D.; Katayama, I. Present-day ultrahigh-pressure 1191 conditions of coesite inclusions in zircon and garnet: Evidence from 1192 laser Raman micro-spectroscopy. Geology 1999, 27, 979-982. 1193

(72) Izraeli, E. S.; Harris, J. W.; Navon, O. Raman barometry of 1194 diamond formation. Earth Planet. Sci. Lett. 1999, 173, 351-360. 1195 (73) Nasdala, L.; Hofmeister, W.; Harris, J. W.; Glinnemann, J. 1196 Growth zoning and strain patterns inside diamond crystals as revealed 1197 by Raman maps. Am. Mineral. 2005, 90, 745-748. 1198

(74) Noguchi, N.; Abduriyim, A.; Shimizu, I.; Kamegata, N.; Odake, 1199 S.; Kagi, H. Imaging of internal stress around a mineral inclusion in a 1200 sapphire crystal: application of micro-Raman and photoluminescence 1201 spectroscopy. J. Raman Spectrosc. 2013, 44, 147-154. 1202

(75) Enami, M.; Nishiyama, T.; Mouri, T. Laser Raman micro- 1203 spectrometry of metamorphic quartz: A simple method for 1204 comparison of metamorphic pressures. Am. Mineral. 2007, 92, 1205 1303-1315.

1206

(76) Kouketsu, Y.; Nishiyama, T.; Ikeda, T.; Eniami, M. Evaluation 1207 of residual pressure in an inclusion - host system using negative 1208 frequency shift of quartz Raman spectra. Am. Mineral. 2014, 99, 433- 1209 442.

1210

(77) Taguchi, T.; Enami, M.; Kouketsu, Y. Metamorphic record of 1211 the Asemi-gawa eclogite unit in the Sanbagawa belt, southwest Japan: 1212 Constraints from inclusions study in garnet porphyroblasts. J. 1213 Metamorph. Geol. 2019, 37, 181-201.

1214

(78) Zhong, X.; Andersen, N. H.; Dabrowski, M.; Jamtveit, B. Zircon 1215 and quartz inclusions in garnet used for complementary Raman 1216 thermobarometry: application to the Holsn $\varnothing$ y eclogite, Bergen Arcs, 1217 Western Norway. Contrib. Mineral. Petrol. 2019, 174, 50-66. 1218

(79) Darot, M.; Gueguen, Y. Slow crack growth in minerals and 1219 rocks: theory and experiments. Pure Appl. Geophys. 1986, 124, 677- 1220 692.

1221

(80) Mallet, C.; Fortin, J.; Gueguen, Y.; Bouyer, F. Role of the pore 1222 fluid in crack propagation in glass. Mech. Time-Depend. Mater. 2015, 1223 19, 117-133.

1224

(81) Ougier-Simonin, A.; Zhu, W. Effect of the pore pressure 1225 buildup on slowness of rupture propagation. J. Geophys. Res. 2015, 1226 120, 7966-7985. 
1228 (82) Sterner, S. M.; Bodnar, R. J. Synthetic fluid inclusions - VII. Re1229 equilibration of fluid inclusions in quartz during laboratory-simulated 1230 metamorphic burial and uplift. J. Metamorph. Geol. 1989, 7, 243-260. 1231 (83) Vityk, M. O.; Bodnar, R. J.; Schmidt, C. S. Fluid inclusions as 1232 tectonothermobarometers: Relation between pressure-temperature 1233 history and reequilibration morphology during crustal thickening. 1234 Geology 1994, 22, 731-734.

1235 (84) Vityk, M. O.; Bodnar, R. J. Do fluid inclusions in high-grade 1236 metamorphic terranes preserve peak metamorphic density during 1237 retrograde decompression? Am. Mineral. 1995a, 80, 641-644.

1238 (85) Vityk, M. O.; Bodnar, R. J. Textural evolution of synthetic fluid 1239 inclusions in quartz during reequilibration, with applications to 1240 tectonic reconstruction. Contrib. Mineral. Petrol. 1995b, 121, 3091241323.

1242 (86) Raimbourg, H.; Famin, V.; Palazzin, G.; Mayoux, M.; Jolivet, 1243 L.; Ramboz, C.; Yamaguchi, A. Fluid properties and dynamics along 1244 the seismogenic plate interface. Geosphere 2018, 14, 469-491.

1245 (87) Paterson, M.S. Experimental rock deformation - The brittle field, 1246 Springer Verlag, Berlin, 1978.

1247 (88) Bruno, M. S.; Nakagawa, F. M. Pore pressure influence on 1248 tensile fracture propagation in sedimentary rock. Int. J. Rock Mech. 1249 Min. Sci. Geomech. Abstr. 1991, 28, 261-273.

1250 (89) Austrheim, H. Eclogitization of lower crustal granulites by fluid 1251 migration through shear zones. Earth Planet. Sci. Lett. 1987, 81, 2211252232.

1253 (90) Goncalves, P.; Poilvet, J.-C.; Oliot, E.; Trap, P.; Marquer, D. 1254 How does shear zone nucleate? An example from the Suretta nappe 1255 (Swiss Eastern Alps). J. Struct. Geol. 2016, 86, 166-180.

1256 (91) Leydier, T.; Goncalves, P.; Lanari, P.; Oliot, E. On the 1257 petrology of brittle precursors of shear zones - An expression of 1258 concomitant brittle deformation and fluid-rock interactions in the 1259 'ductile' continental crust? J. Metamorph. Geol. 2019, 37, 1129-1149. 1260 (92) Den Brok, B. Effect of microcracking on pressure-solution 1261 strain rate: The Gratz grain-boundary model. Geology 1998, 26, 9151262918.

1263 (93) Nakashima, S.; Matayoshi, H.; Yuko, T.; Michibayashi, K.; 1264 Masuda, T.; Kuroki, N.; Yamagashi, H.; Ito, Y.; Nakamura, A. Infrared 1265 microspectroscopy analysis of water distribution in deformed and 1266 metamorphosed rocks. Tectonophysics 1995, 245, 263-276. 